$$
\begin{aligned}
& \text { QUESTÕES DE } \\
& \text { FISICA }
\end{aligned}
$$

Resolvidas com Linguagem C

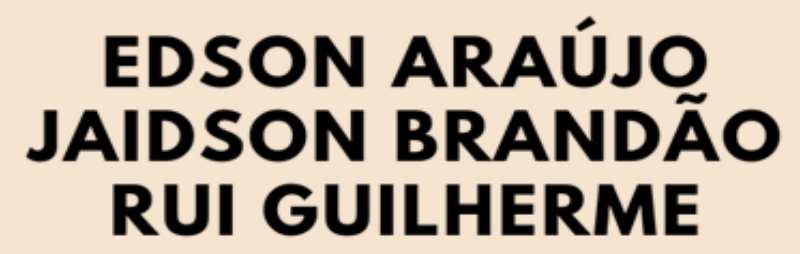




\section{Questões de Física resolvidas com linguagem C}

EDSON ARAÚJO DA SILVA

JAIDSON BRANDÃO DA COSTA

RUI GUILHERME DE DEUS CARVALHO RIBEIRO 


\section{Apresentação}

Este livro tem como objetivo facilitar a resolução de questões de Física no que diz respeito à base de assunto que denotam um grau maior nos problemas de aprendizado por partes dos alunos. Pensando na melhor maneira da elaboração, aplicação e resoluções de problemas envolvendo exercícios, optou-se pela junção dos conceitos e com uma abordagem em linguagem de programação de computadores e em especial a linguagem de programação C. Para incrementar as resoluções aplicaram-se alguns exemplos em programas em $\mathrm{C}$, a fim de que as soluções tenham inúmeros cenários com valores diferentes e assim demonstrando as resoluções dos problemas do mundo real e não apenas fixado ao um mero exercício. Aplicou-se dessa forma para que o aluno realize a implementação. Tendo em vista que há uma abordagem computacional neste livro, logo o público indicado para esta obra são alunos iniciantes em programação. O livro foi elaborado por: Edson Araújo da Silva, Graduado em Licenciatura em Física e Tecnologia da Construção Civil, Especialista em Matemática e Física e Mestre em Educação. Outro autor é Jaidson Brandão da Costa, Graduado em Sistemas de Informação, Especialista em Engenharia de Software e Mestre em Engenharia de Processos. Outro autor foi Rui Guilherme de Deus Carvalho Ribeiro, Graduado em Matemática, Especialista em matemática financeira e estatística e Mestrando em Matemática. Todos os autores são Professores do Instituto Federal de Educação, Ciência e Tecnologia do Amazonas - Campus Avançado Manacapuru. 


\section{Sumário}

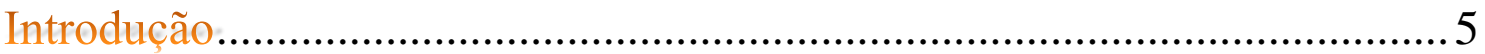

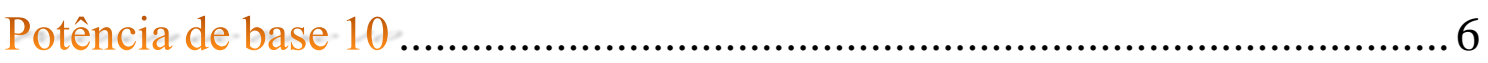

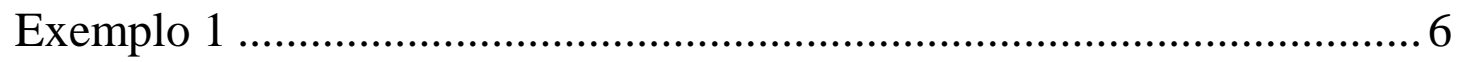

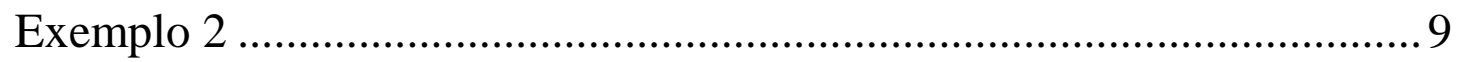

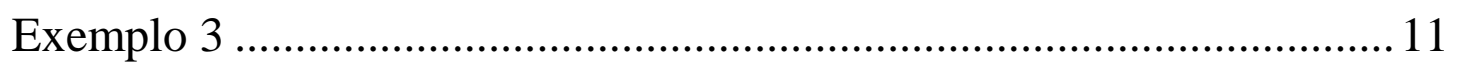

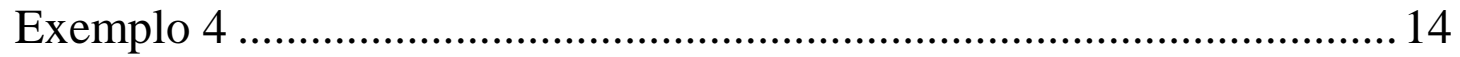

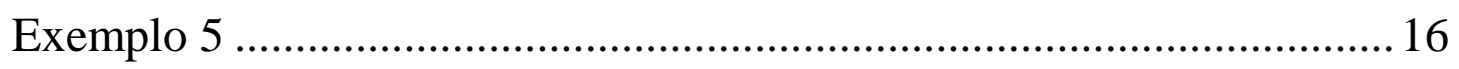

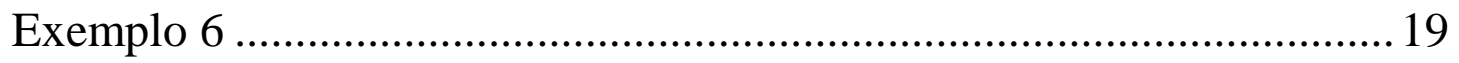

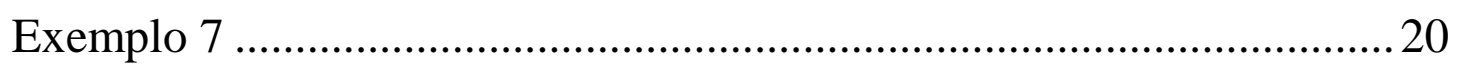

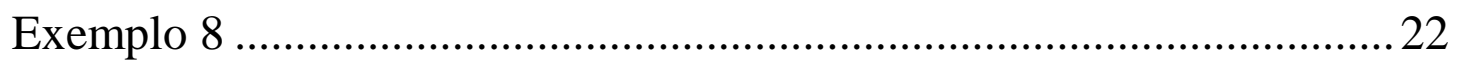

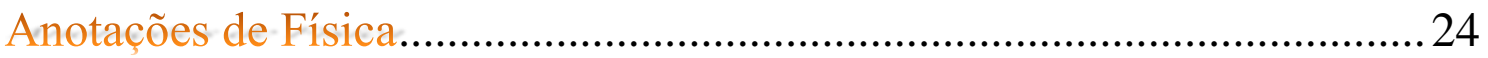

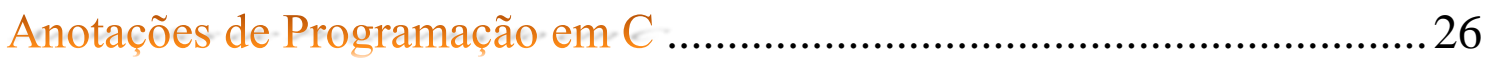

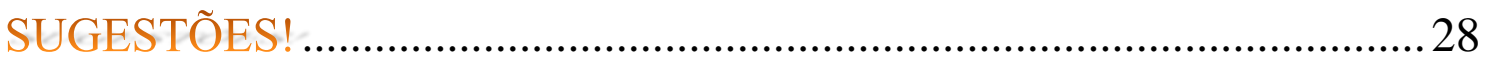

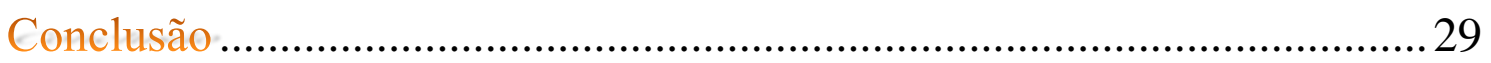




\section{Introdução.}

É importante uma concepção interdisciplinar, para estabelecer um diálogo entre as disciplina de Física e Informática, para que através de algumas situações do cotidiano dos estudantes, possamos introduzir problemas a serem resolvidos de forma tradicional e em seguida com o desenvolvimento de comandos na linguagem $\mathrm{C}$, aferindo se esta nova forma de abordar o assunto conduziu a uma Aprendizagem Significativa, onde os conceitos apresentam relevância na estrutura cognitiva dos estudantes, desta forma produzindo uma nova motivação para aprender e contribuir de forma positiva, tanto na formação científica desse discente, quanto em sua formação profissional.

A Física tinha na antiguidade o propósito de entender, prever e, se possível, controlar alguns fenômenos da natureza, entretanto, ainda hoje, com todos os avanços tecnológicos, estamos distantes de atingir essa meta, mas, talvez com a descoberta dos computadores quânticos, muitos desses mistérios poderão ser desvendados. E para explicar esses fenômenos naturais precisaremos da Matemática, que segundo Galileo Galileo, "A Matemática é o alfabeto que Deus usou para escrever o Universo", portanto vamos iniciar com um pouco de matemática.

O interessante que o aluno após codificar os exemplos deste livro poderá revisar de forma mais simplória o conteúdo abordado, facilitando dessa forma a concretização do aprendizado. 


\section{Potência de base 10}

Iniciaremos relembrando, a potenciação é a operação matemática escrita na forma $\mathrm{a}^{\mathrm{n}}$, onde 'a' é a base e ' $\mathrm{n}$ ' o expoente que indica o número de vezes que a base será multiplicada.

\section{Exemplo 1}

$2^{3}=2.2 \cdot 2=8$

$3^{2}=3.3=9$

$5^{4}=5 \cdot 5 \cdot 5 \cdot 5=625$

Para explorarmos este exemplo não apenas com o cenário descrito acima, podemos propor um programa em linguagem $C$ para inserção de variáveis números para diversas simulações. A linguagem $\mathrm{C}$ foi criada a partir do $\mathrm{B}$ por Dennis Ritchie e implementada em 1972. Ela é independe do hardware sendo possível escrever programas que sejam portáteis para a maioria dos computadores. A figura 1 demonstra o programa desenvolvido para simular o exemplo 1 deste livro.

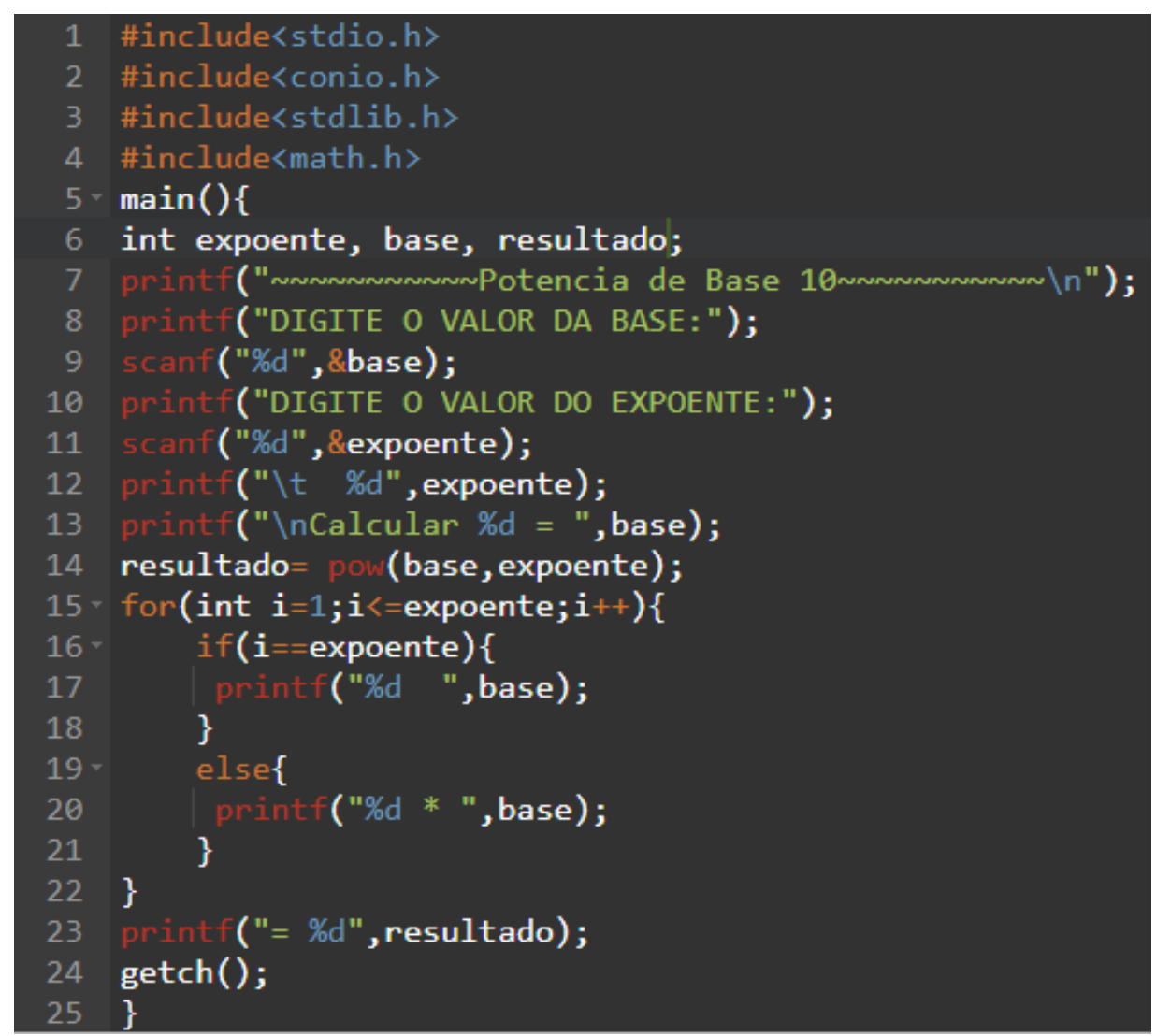

Figura 1 - Programa em C do exemplo 1 
Para entendermos melhor como funciona o programa demonstraremos como são inseridos os dados e apresentados na tela do computador, claro com as simulações das informações do exemplo 1. A figura 2, 3 e 4 ilustra as simulações.

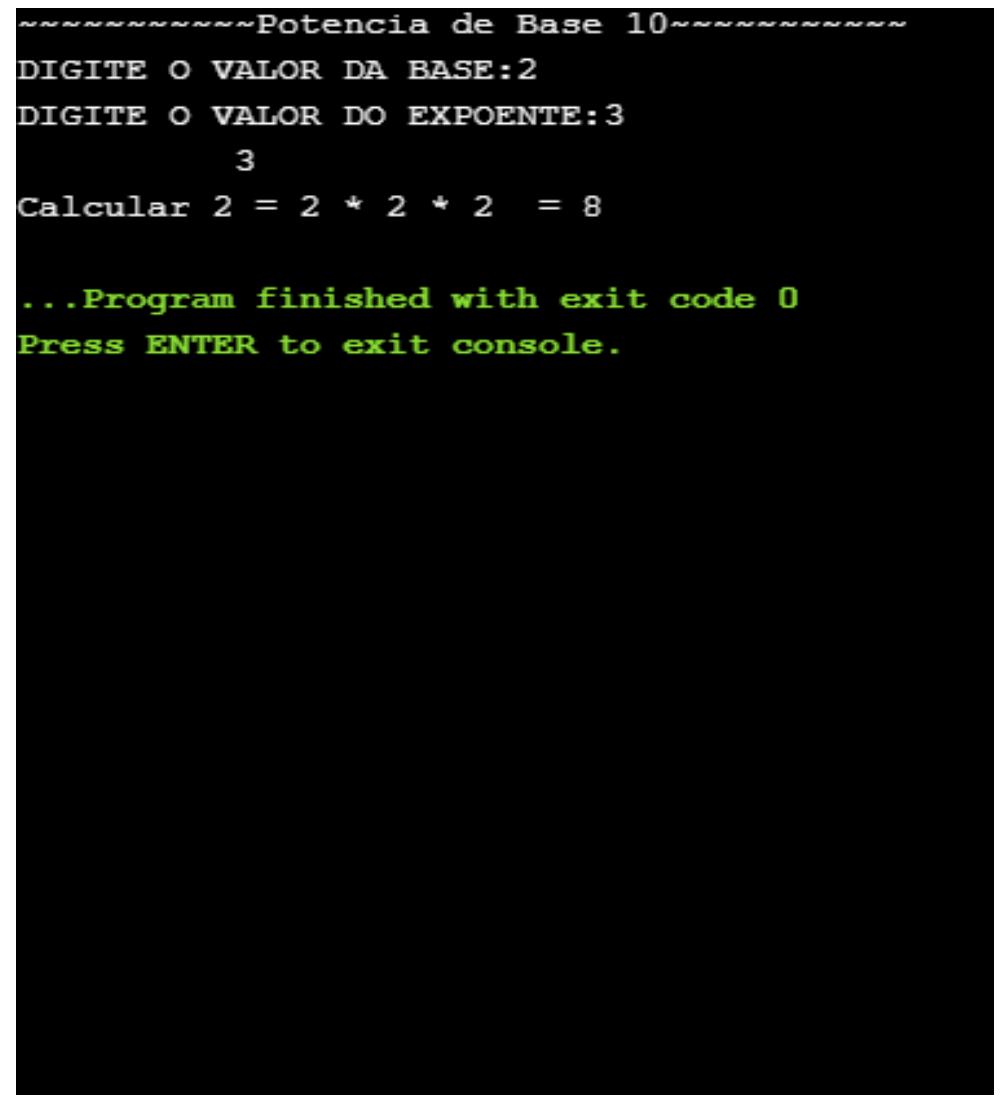

Figura 2 - Programa em C do exemplo 1 em execução

Para segunda simulação a figura 3 ilustra os dados. 


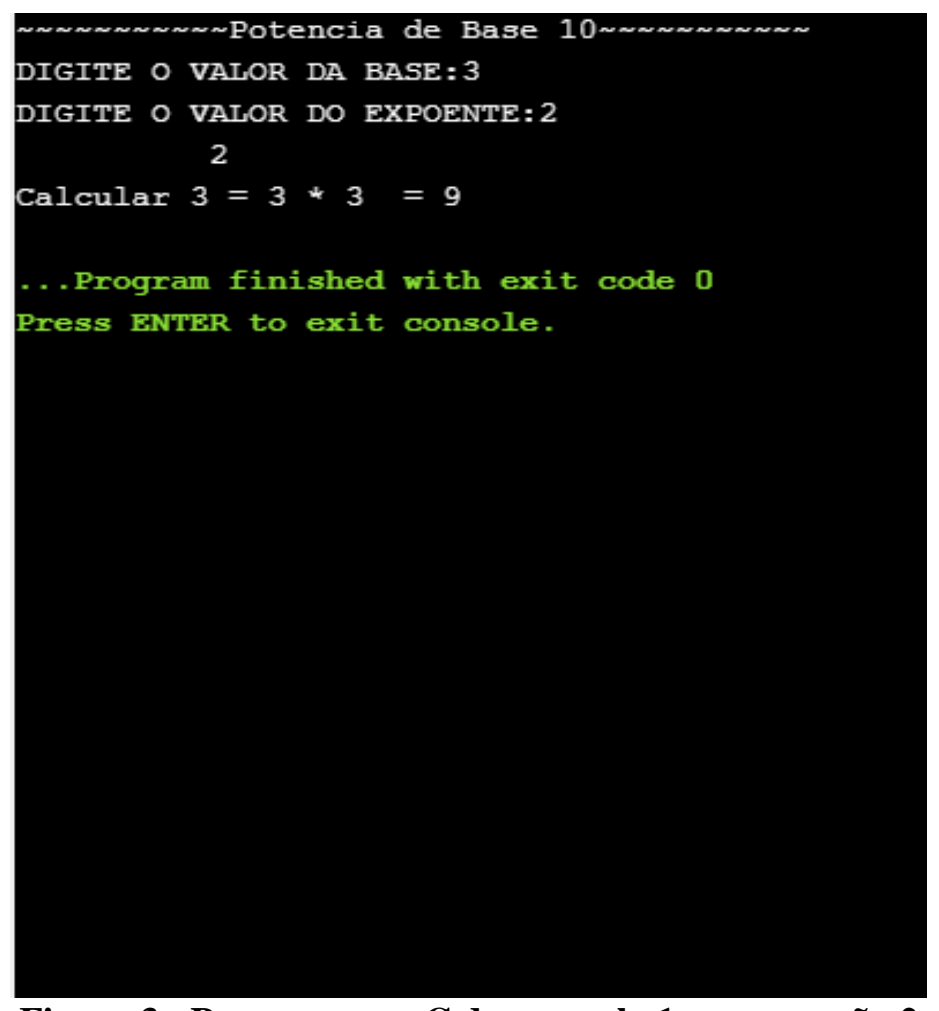

Figura 3 - Programa em C do exemplo 1 em execução 2

Para terceira simulação a figura 4 ilustra os dados.

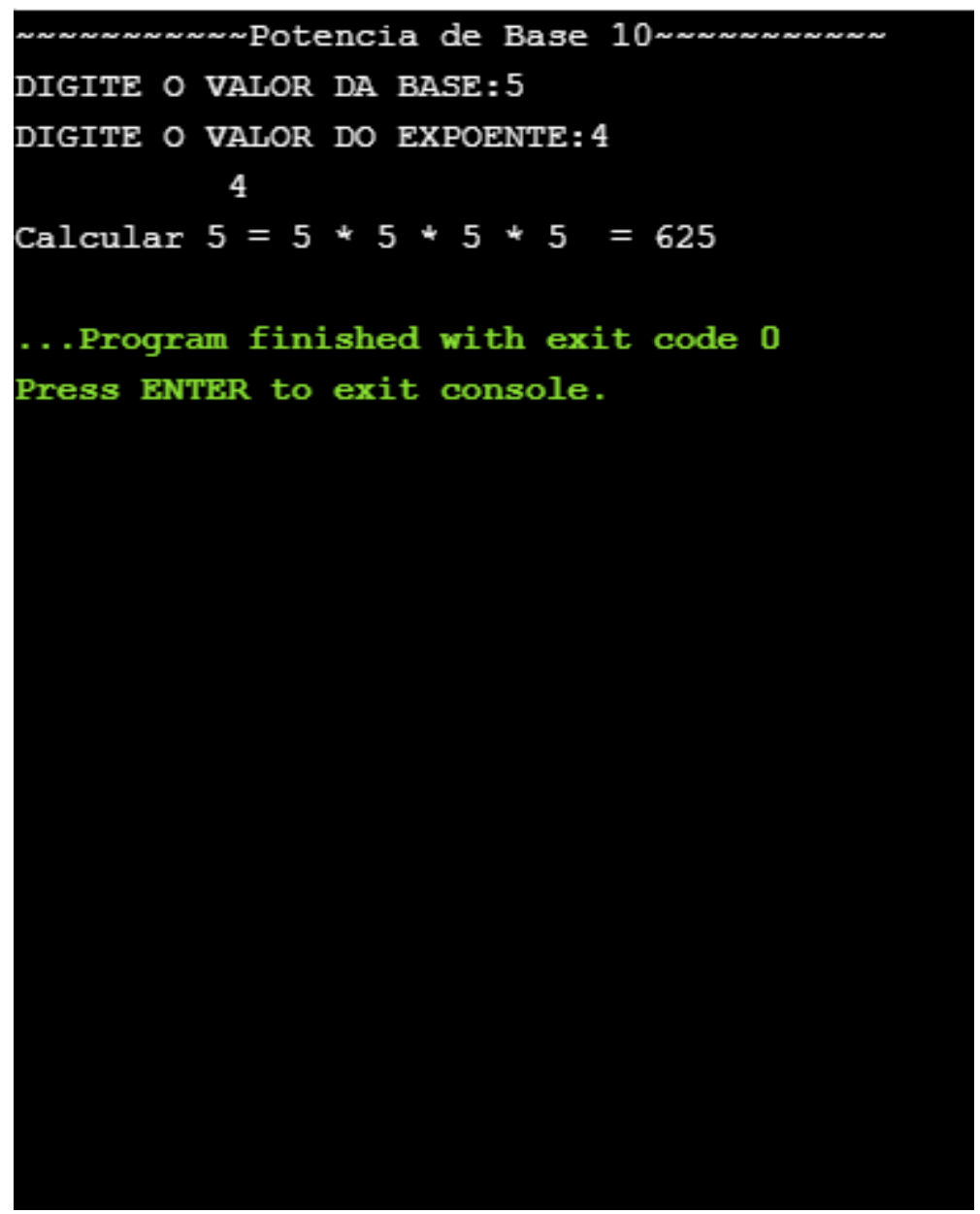

Figura 4 - Programa em C do exemplo 1 em execução 3 


\section{Atencão!}

$1000^{\circ}=1$ (todo número elevado ao expoente zero terá como resultado 1$)$

Mas porque usar potência na 10 ? Na Física, muitas vezes usamos números muito grandes como por exemplo o raio da Terra, que é aproximadamente 6400000 metros (m), ou muito pequenos como o diâmetro do maior vírus conhecido (megavirus chilensis) 0,000 $00044 \mathrm{~m}$. Podemos representar esses números utilizando a potência de 10, para isso teremos que fazer duas coisas, modificar a posição da vírgula no número e contar quantos algarismos ela se deslocou, quando a vírgula se desloca para esquerda o expoente da potência de 10 é positivo (+) se desloca para direita será negativo (-) .

\section{Exemplo 2}

a) $6400000,0=6,4 \times 10^{6}$ metros, perceba que a vírgula foi deslocada 6 casas para a esquerda, expoente positivo.

Veremos na figura 5 como o programa em $\mathrm{C}$ apresenta a solução para simulação dessa situação.

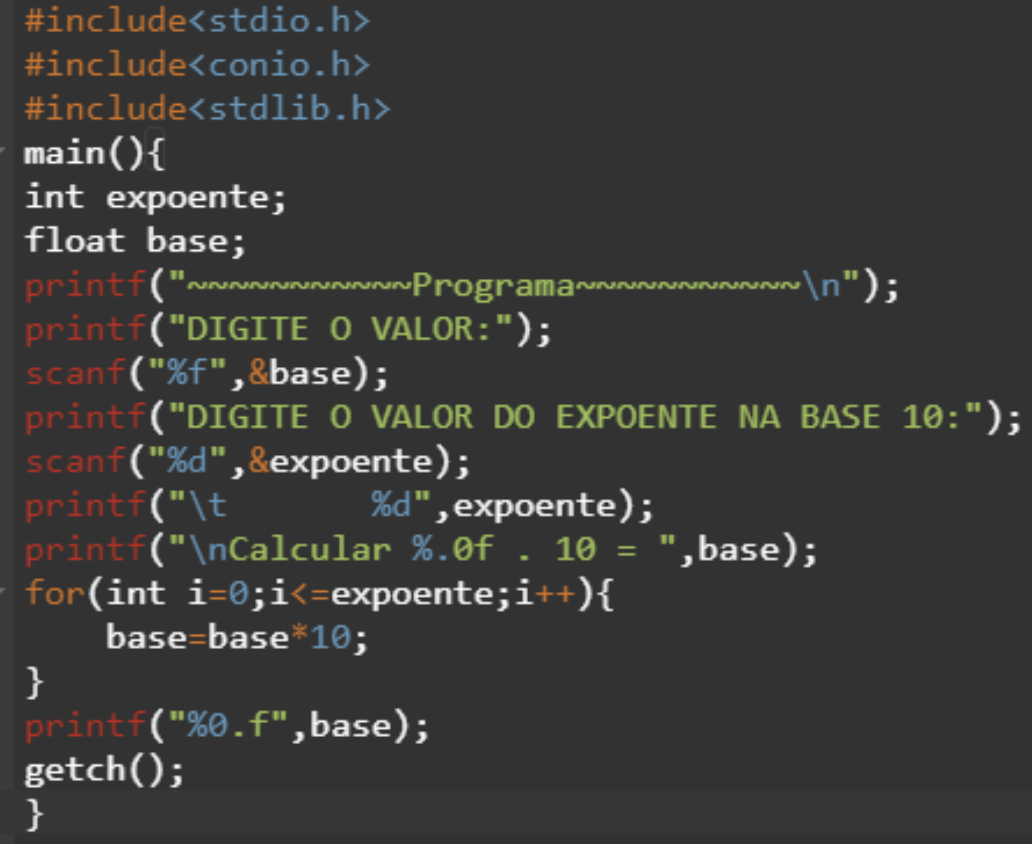

Figura 5 - Programa em C do exemplo 2 A

Para simulação a figura 6 ilustra os dados. 


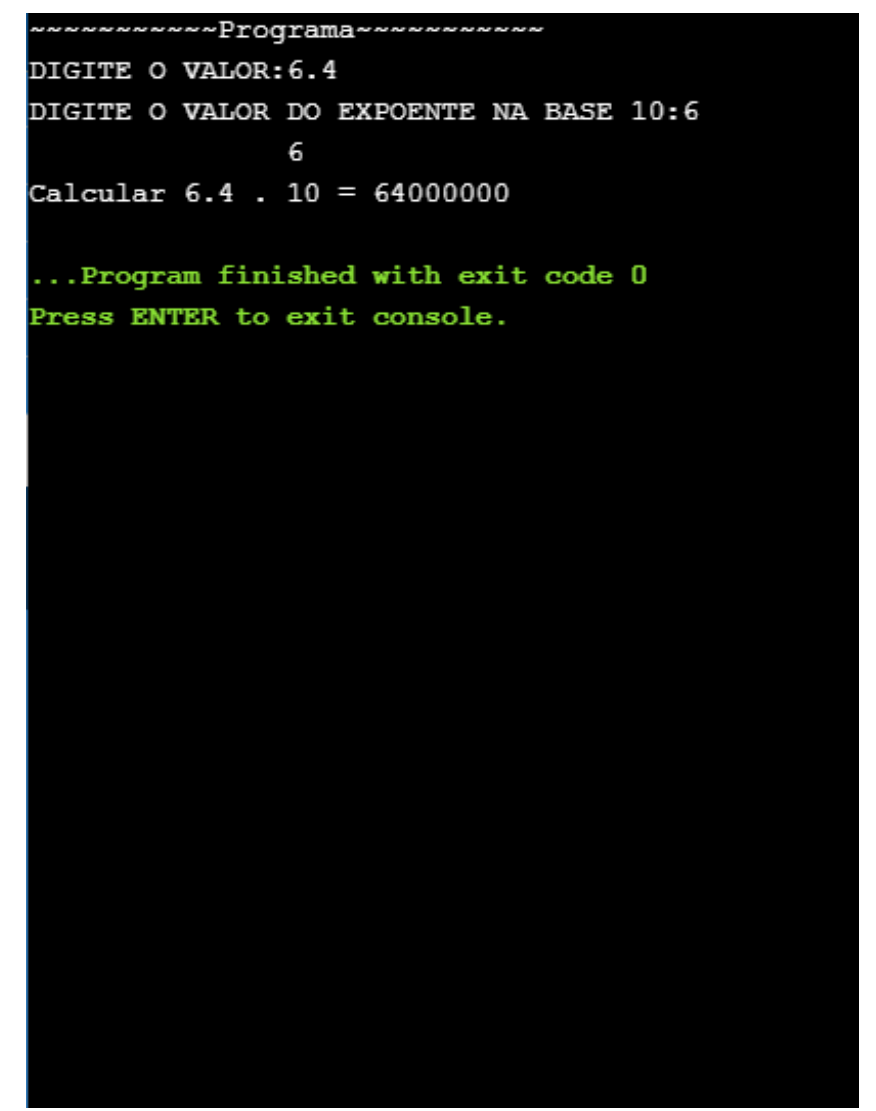

Figura 6 - Programa em C do exemplo 2 A em execução

b) $0,00000044=4,4 \times 10^{-7}$ metros, a vírgula avançou 7 casas para a direita, expoente negativo.

Veremos na figura 7 o programa em $C$ e na figura 8 a execução dele.

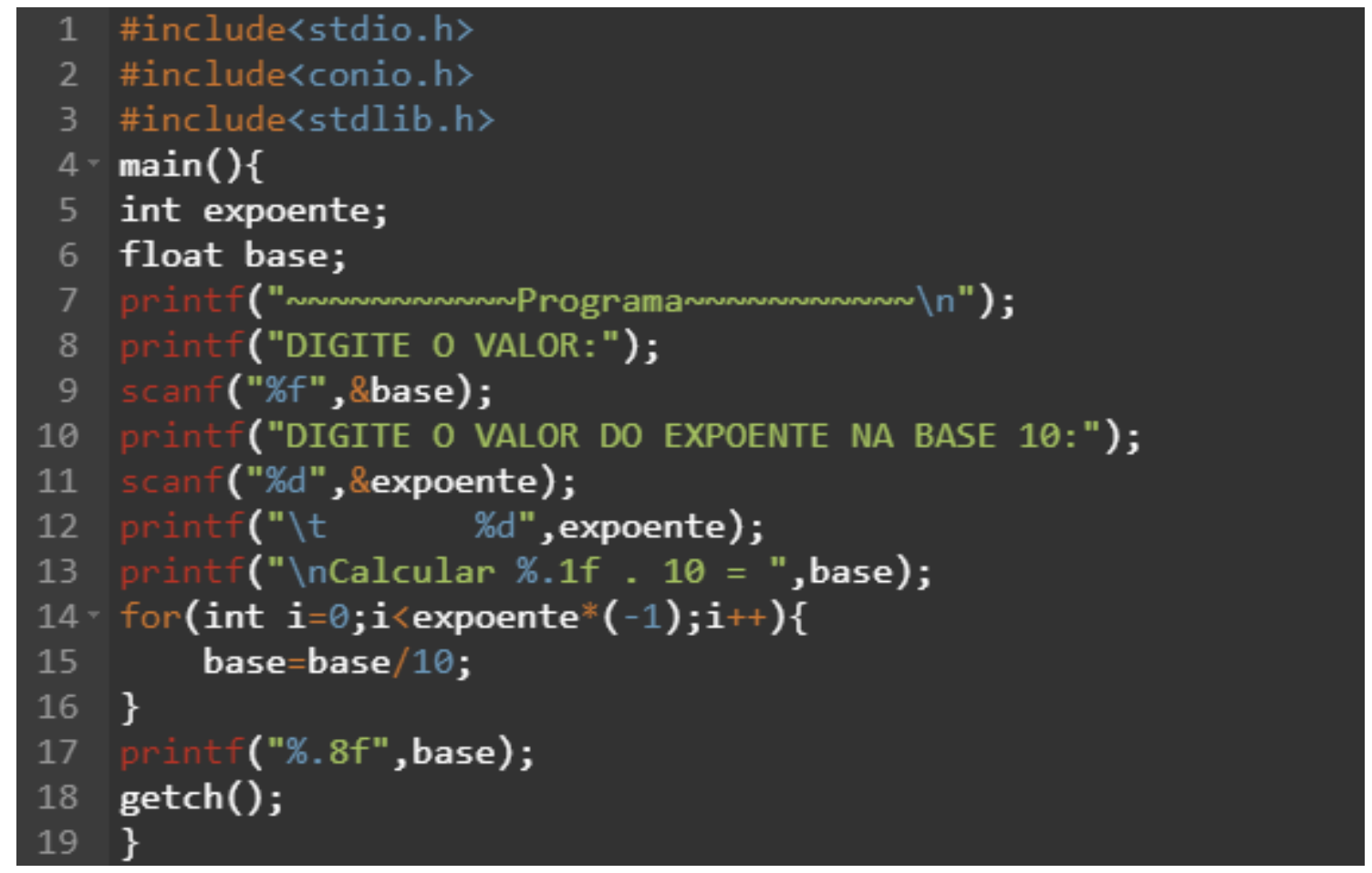


Figura 7 - Programa em C do exemplo 2 B

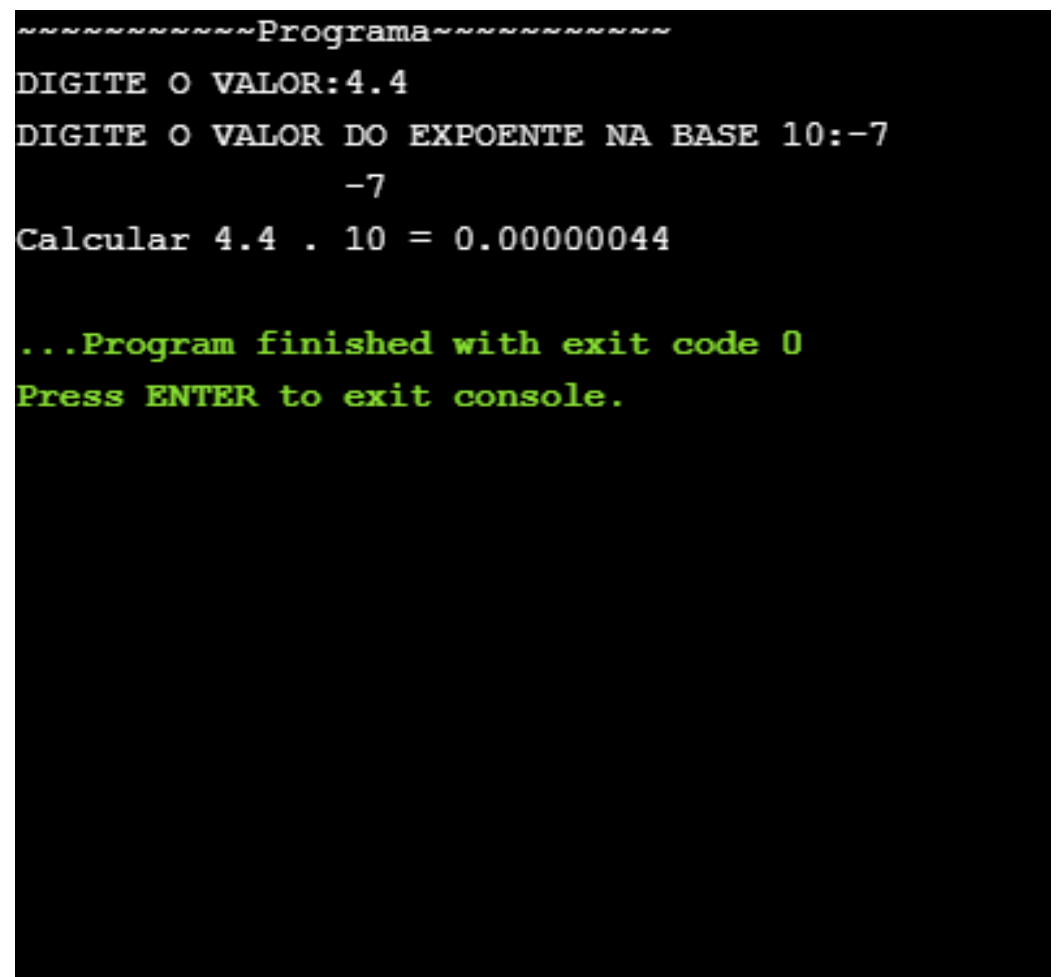

Figura 8 - Programa em C do exemplo 2 B em execução

Utilizando essa mesma ideia, podemos fazer alguns cálculos de forma simples, aplicando duas propriedades da potenciação, quando multiplicamos potência de mesma base mantem a base e somamos os expoentes, portanto $10^{\mathrm{a}} \times 10^{\mathrm{b}}=10^{\mathrm{a}+\mathrm{b}}$.

\section{Exemplo 3}

Utilizaremos o mesmo programa para calcular os problemas do exemplo 3.

Conforme a figura 9.

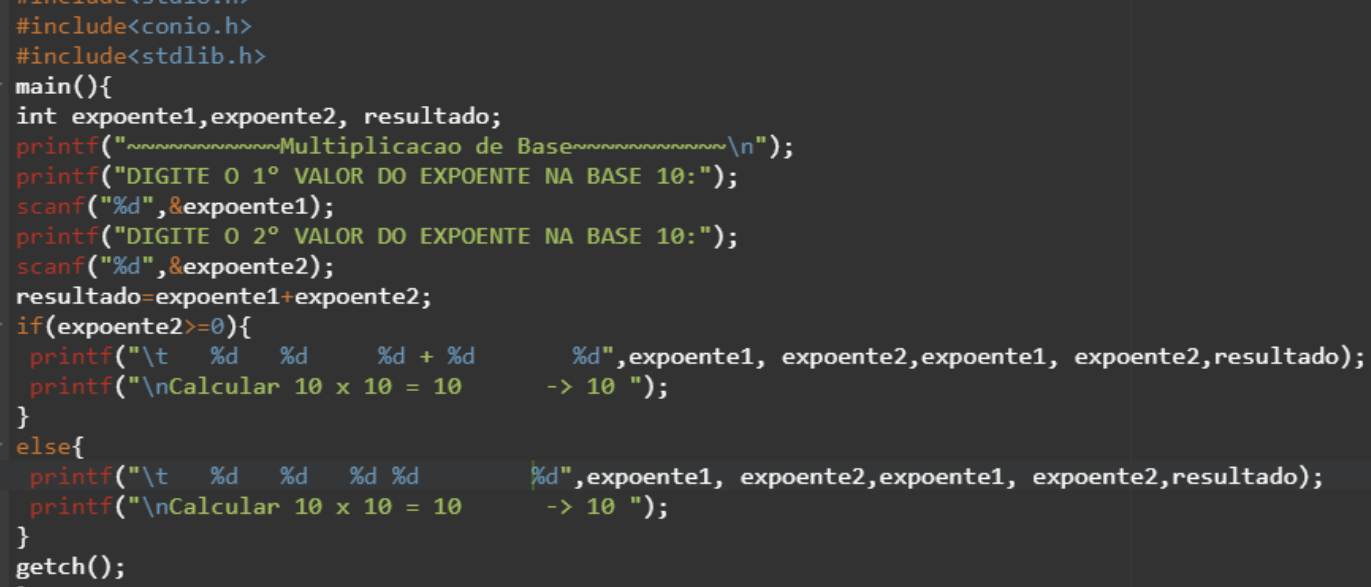

Figura 9 - Programa em $\mathrm{C}$ de as contas do exemplo 3 
a) $10^{3} \times 10^{4}=10^{3+4}=10^{7}$

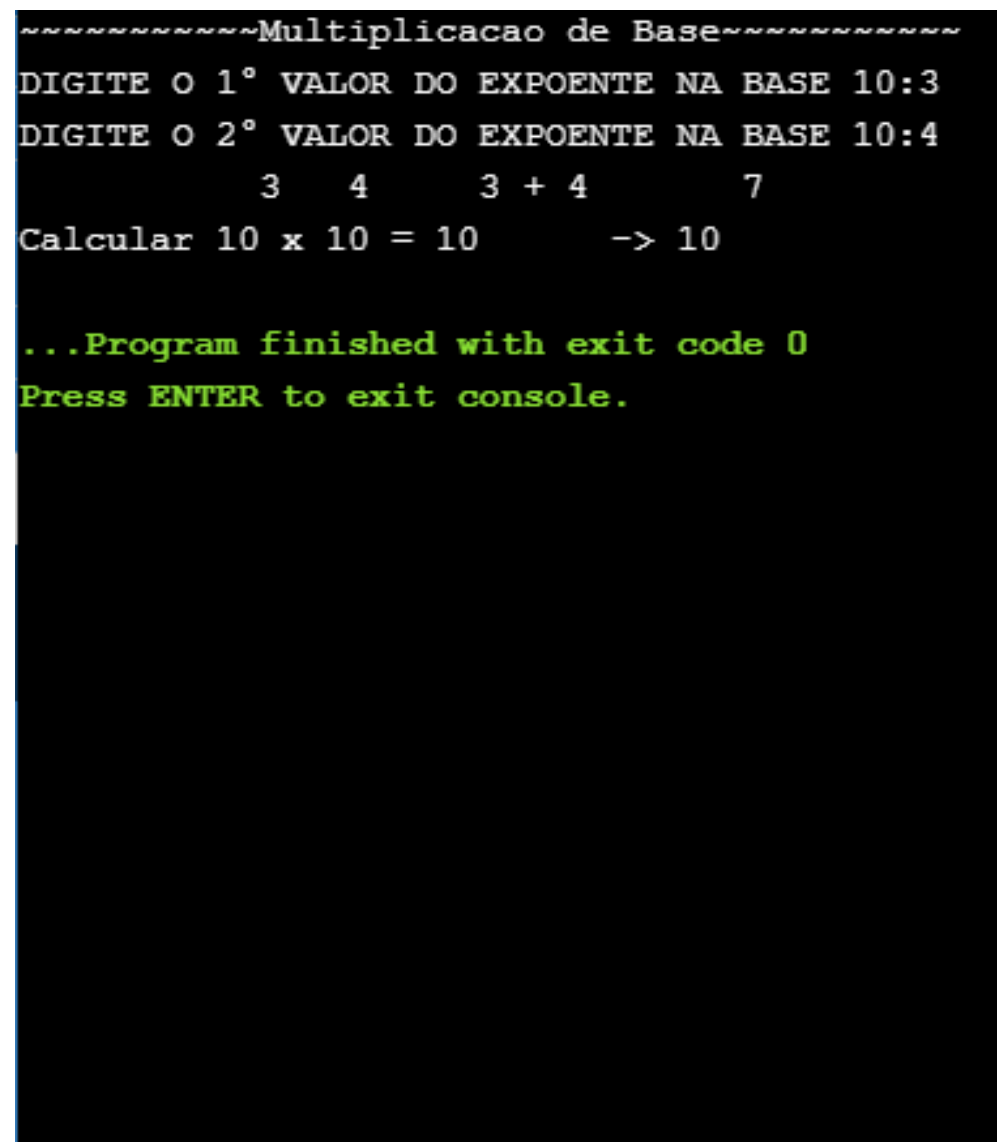

Figura 10 - Programa em C do exemplo 3 A em execução

b) $10 \times 10=10^{1+1}=10^{2}$ (número sem expoente está elevado a $1^{\text {a }}$ potência)

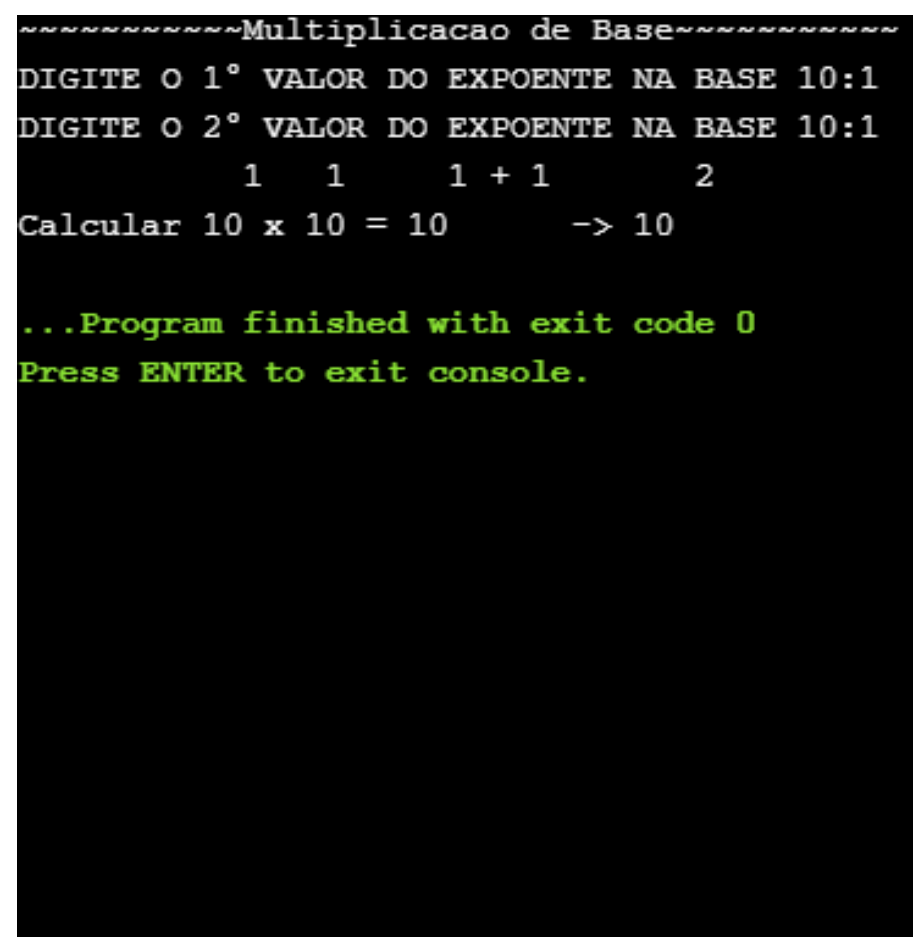

Figura 11 - Programa em C do exemplo 3 B em execução 
c) $10^{5} \times 10^{-2}=10^{5-2}=10^{3}$

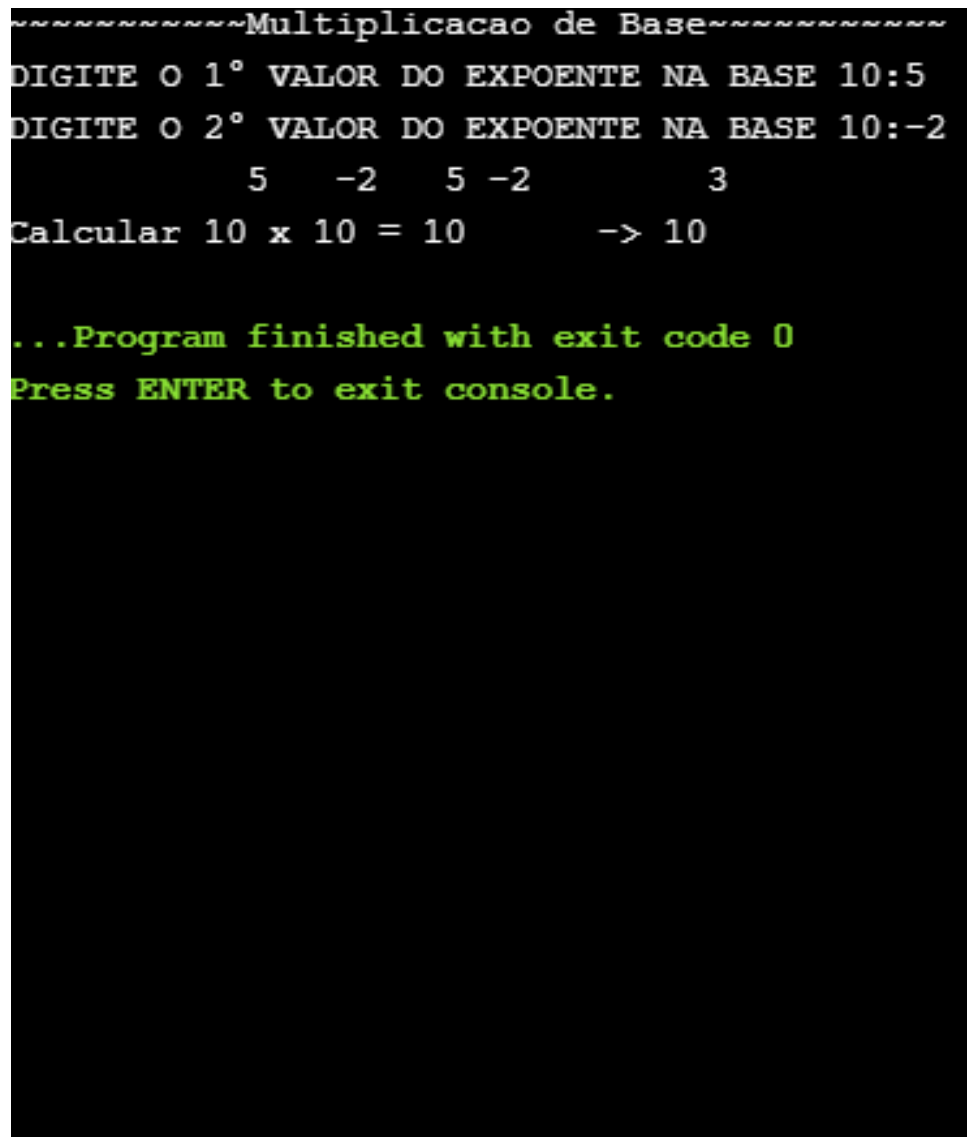

Figura 12 - Programa em C do exemplo $3 \mathrm{C}$ em execução

d) $10^{-5} \times 10^{2}=10^{-5+2}=10^{-3}$

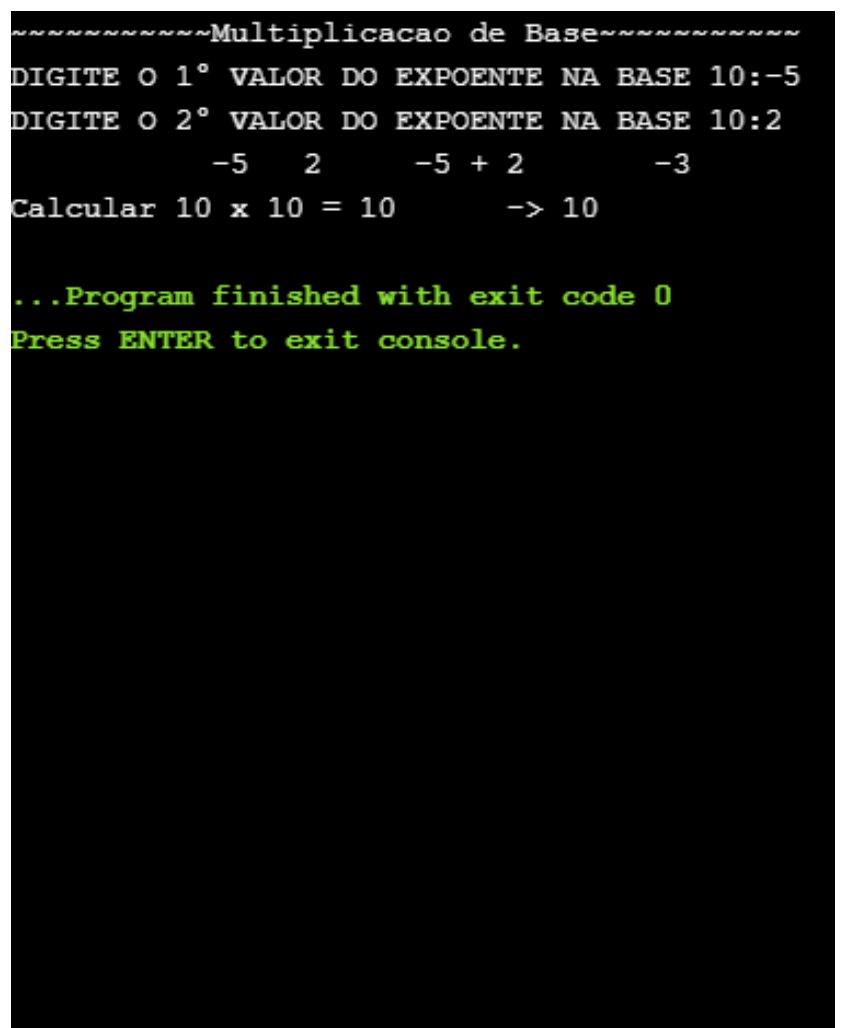

Figura 13 - Programa em C do exemplo 3 D em execução 
Na divisão de potência de mesma base mantem a base e subtraímos os expoentes, portanto $10^{\mathrm{a}}: 10^{\mathrm{b}}=10^{\mathrm{a}-\mathrm{b}}$.

\section{Exemplo 4}

Utilizaremos o mesmo programa para calcular os problemas do exemplo 4 .

Conforme a figura 14 .

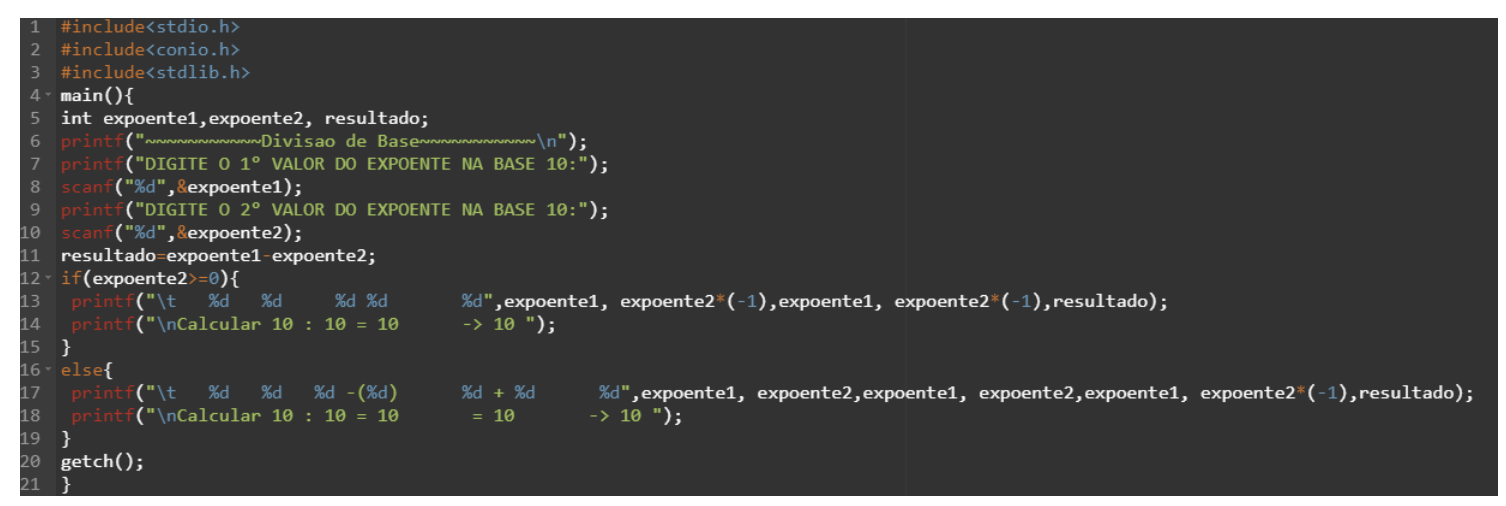

Figura 14 - Programa em C do exemplo 4

a) $10^{3}: 10^{4}=10^{3-4}=10^{-1}$

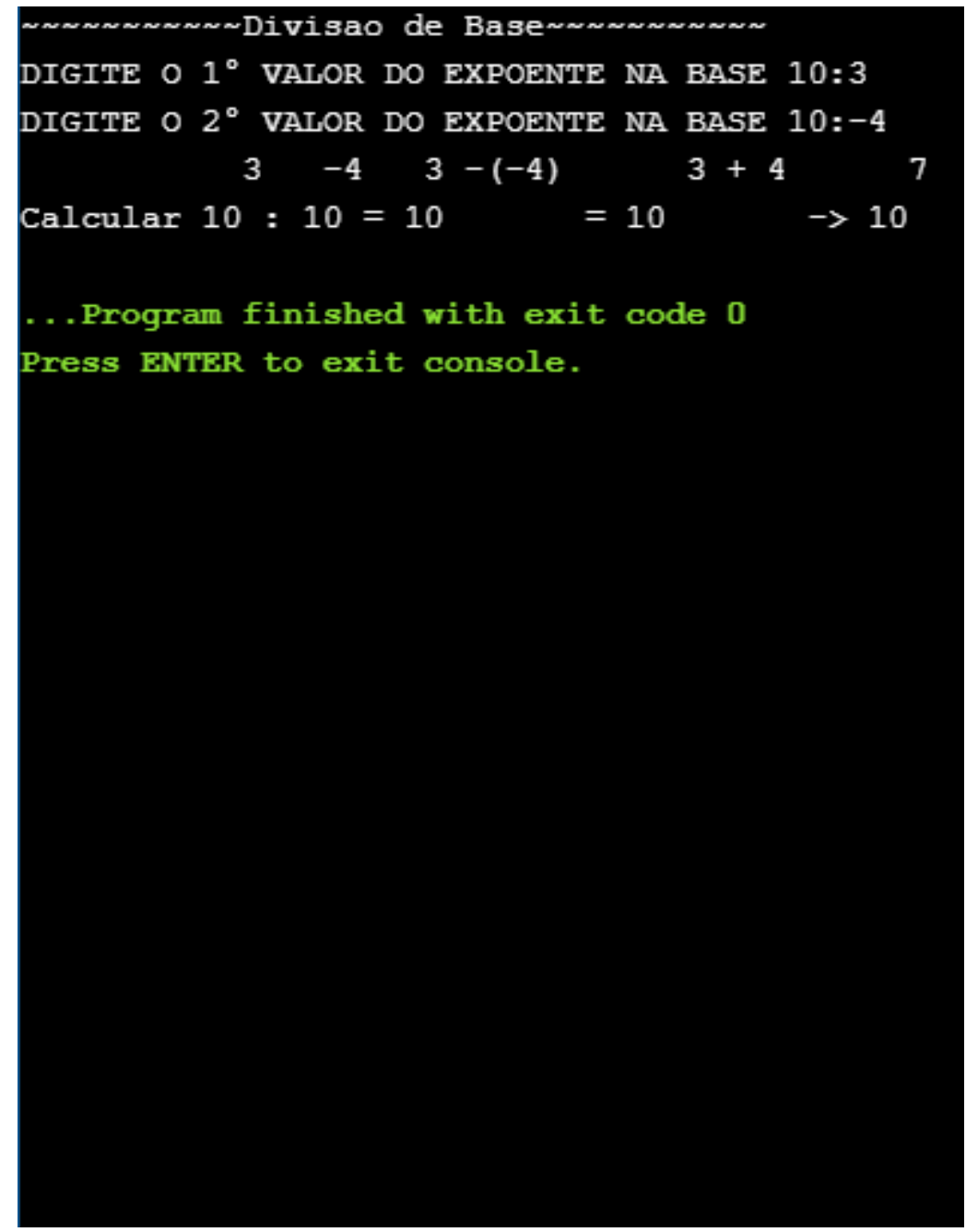

Figura 15 - Programa em C do exemplo 4 A em execução 
b) $10: 10=10^{1-1}=10^{0}=1$

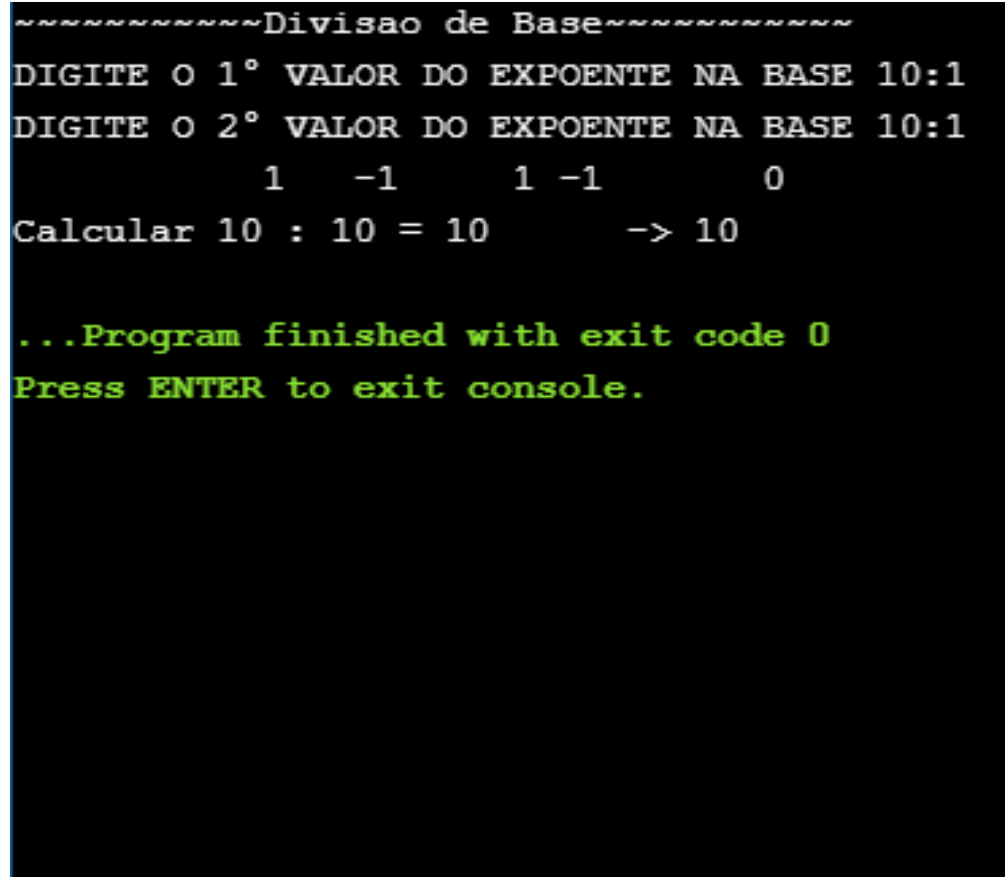

Figura 16 - Programa em C do exemplo 4 B em execução

c) $10^{5}: 10^{-2}=10^{5-(-2)}=10^{5+2}=10^{7}$

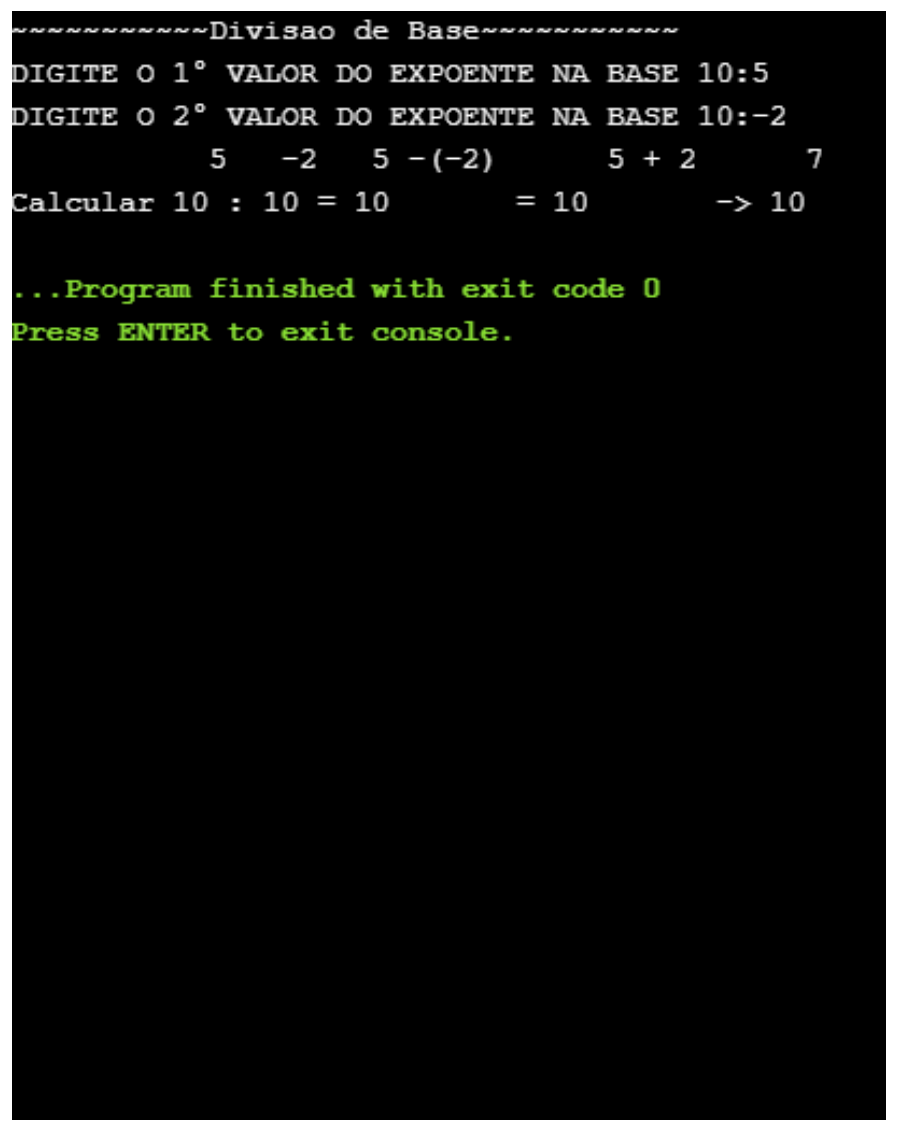

Figura 17 - Programa em C do exemplo 4 C em execução

d) $10^{-5}: 10^{2}=10^{-5-2}=10^{-7}$ 


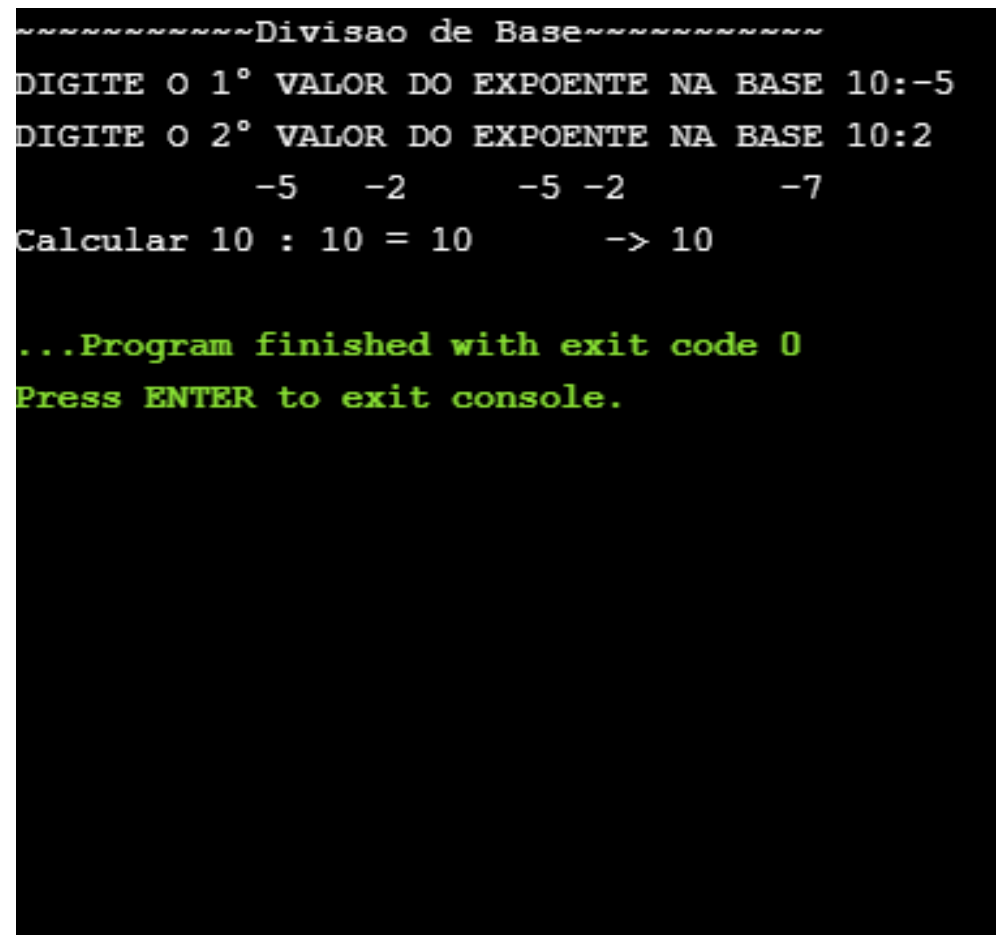

Figura 18 - Programa em C do exemplo 4 D em execução

A partir dos conceitos explicados acima podemos resolver as seguintes divisões:

\section{Exemplo 5}

Utilizaremos o mesmo programa para calcular os problemas do exemplo 5.

Conforme a figura 19.

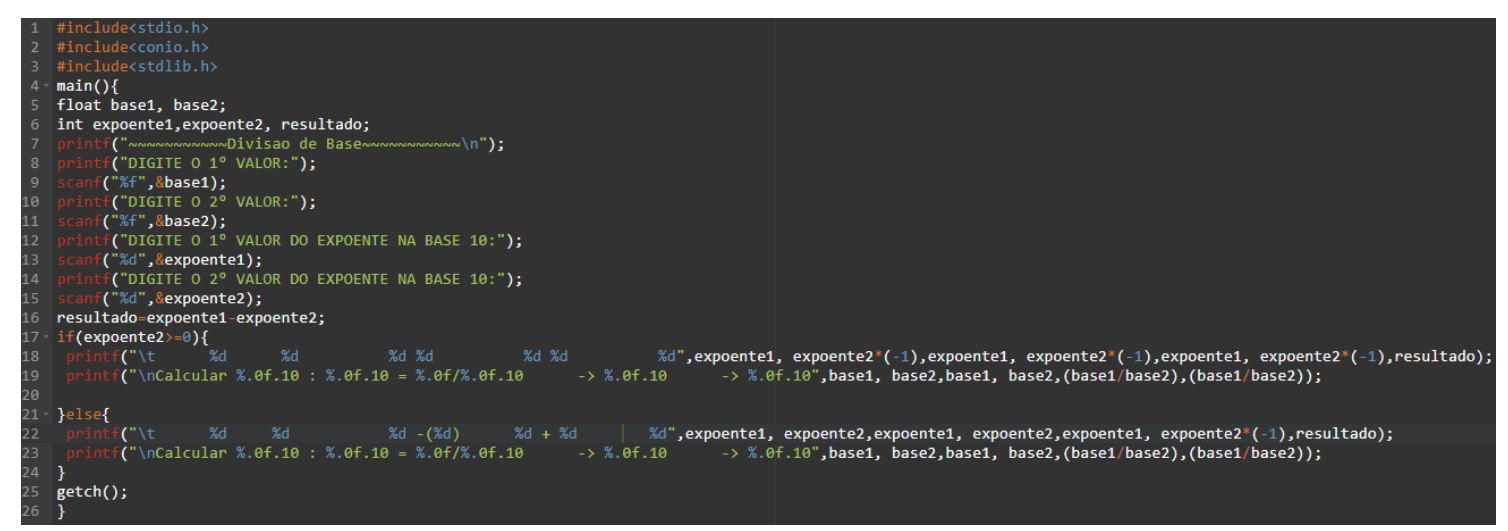

Figura 19 - Programa em C do exemplo 5

a) $0,000036: 0,012$ ou $\frac{36 \times 10^{-6}}{12 \times 10^{-3}}$ podemos dividir em duas etapas:

$\frac{36}{12}=3$ e $\quad \frac{10^{-6}}{10^{-3}}=10^{-6+3}=10^{-3}$ nossa resposta será $3 \times 10^{-3}=0,003$ 


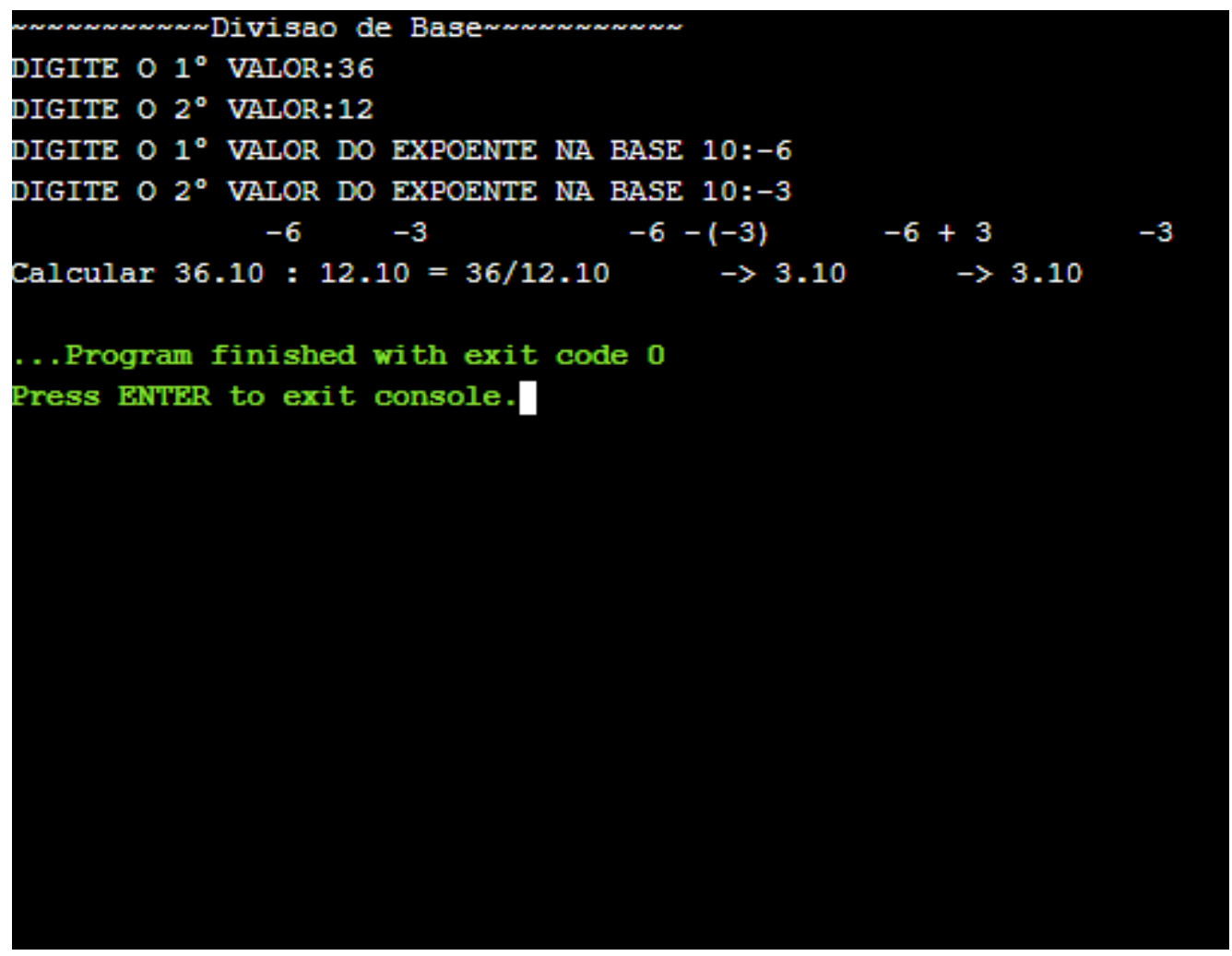

Figura 20 - Programa em C do exemplo 5 A em execução

b) $68000: 0,017$ ou $\frac{68 \times 10^{3}}{17 \times 10^{-3}}$ podemos dividir em duas etapas:

$\frac{68}{17}=4$ e $\frac{10^{3}}{10^{-3}}=10^{3+3}=10^{6}$ nossa resposta será $4 \times 10^{6}=4000000$ 


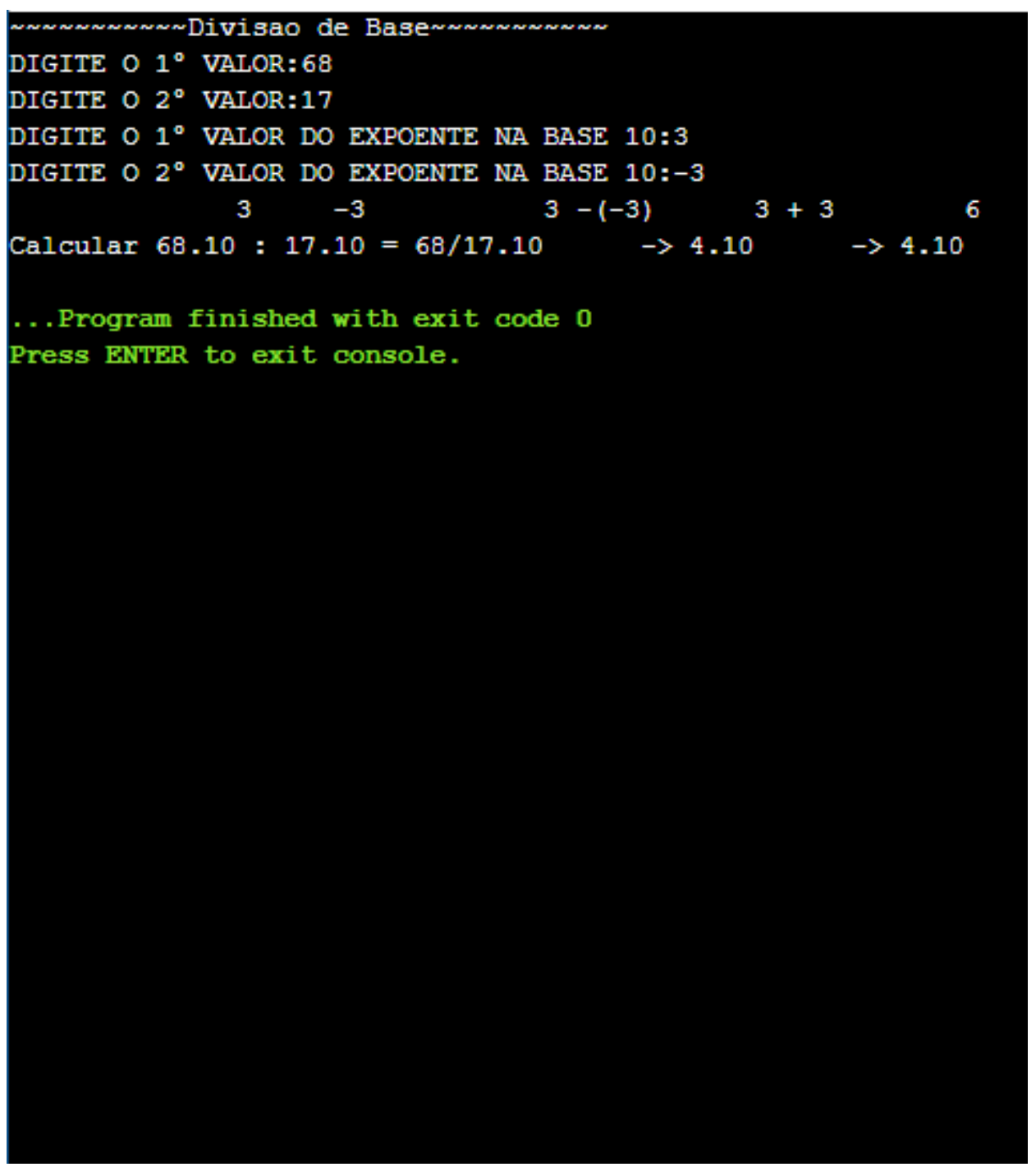

Figura 21 - Programa em C do exemplo 5 B em execução

Vamos falar sobre unidades de medidas, que são usadas para quantificar grandezas físicas como a massa, comprimento, temperatura, velocidade, força etc; para padronizar, temos o Sistema Internacional de Unidades (SI) que define qual unidade devemos utilizar, assim, quando medimos uma determinada distância utilizamos a unidade metro (m) no SI. Costumamos utilizar o mnemônico 'mks', distancia em metros (m), massa em quilograma (k) e tempo em segundos (s). Precisamos converter unidades para resolver alguns exercícios e para isso utilizamos o método de cadeia, que usa uma propriedade da Matemática para sua utilização, ela garante que uma fração permanece igual se multiplicarmos seu numerador e denominador pelo mesmo número. 


\section{Exemplo 6}

a) $\frac{3}{8} \times \frac{5}{5}=\frac{15}{40} \quad$ ou seja 15/40 é igual $3 / 8$

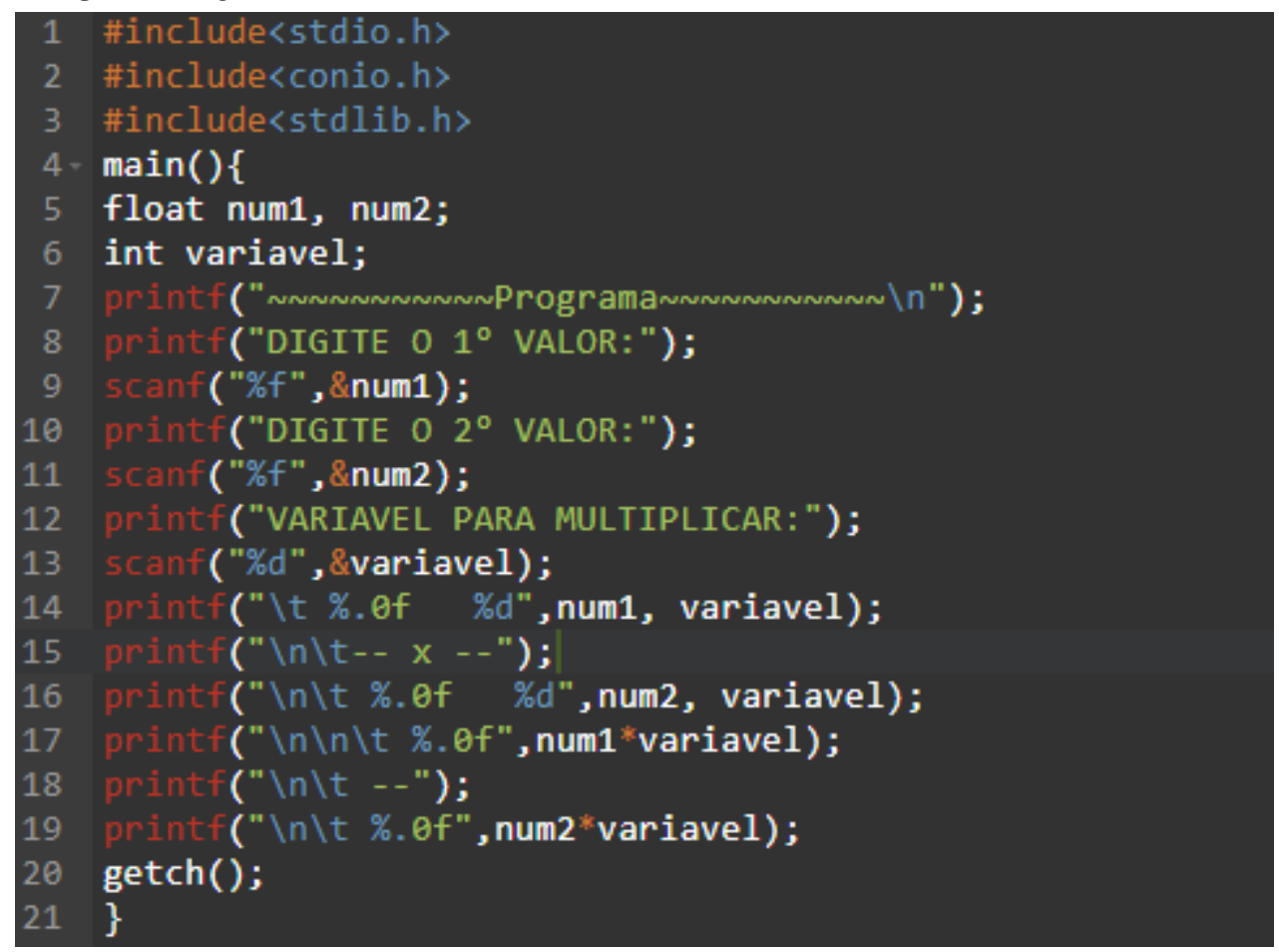

Figura 22 - Programa em C do exemplo 6 A

Execução do programa logo abaixo:

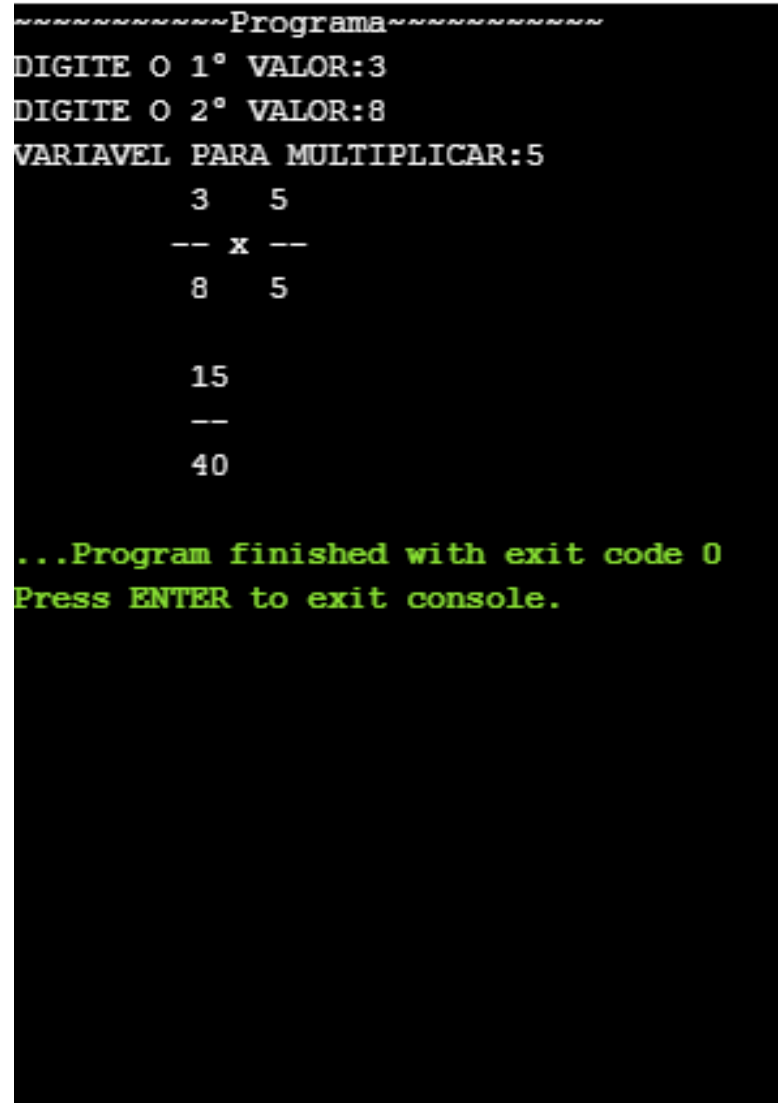

Figura 22 - Programa em C do exemplo 6 A em execução 
Vamos usar essa ideia para converter unidades para o Sistema Internacional de Unidades (SI).

Mudança de unidades usando o método da conversão em cadeia.

\section{Exemplo 7}

Mudar unidade de quilômetro $(\mathrm{km})$ para metros $(\mathrm{m})$. Como sabemos que 1 $\mathrm{km}=1000 \mathrm{~m}$, podemos calcular para $3 \mathrm{~km}$ seu correspondente em metros. Vamos multiplicar numerador e denominador por uma grandeza de mesmo valor com unidades diferentes.

a) $3 \mathrm{~km} \times \underline{1000 \mathrm{~m}}$ podemos cancelar a unidade $\mathrm{km}$ que está no $1 \mathrm{~km} \quad$ numerador e denominador

$3 \mathrm{~km} \times \frac{1000 \mathrm{~m}}{1 \mathrm{~km}}=3000 \mathrm{~m}$

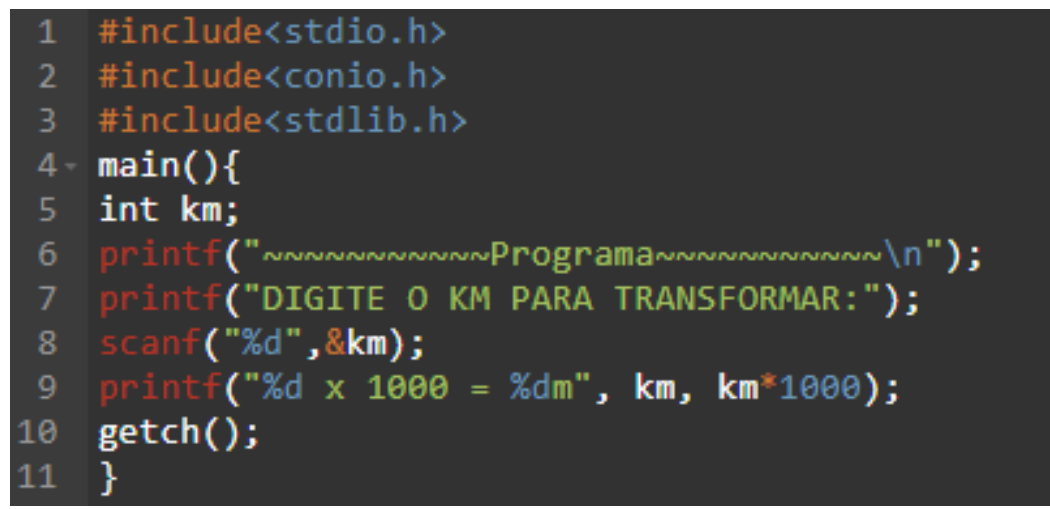

Figura 23 - Programa em C do exemplo 7 A

Abaixo a execução do programa:

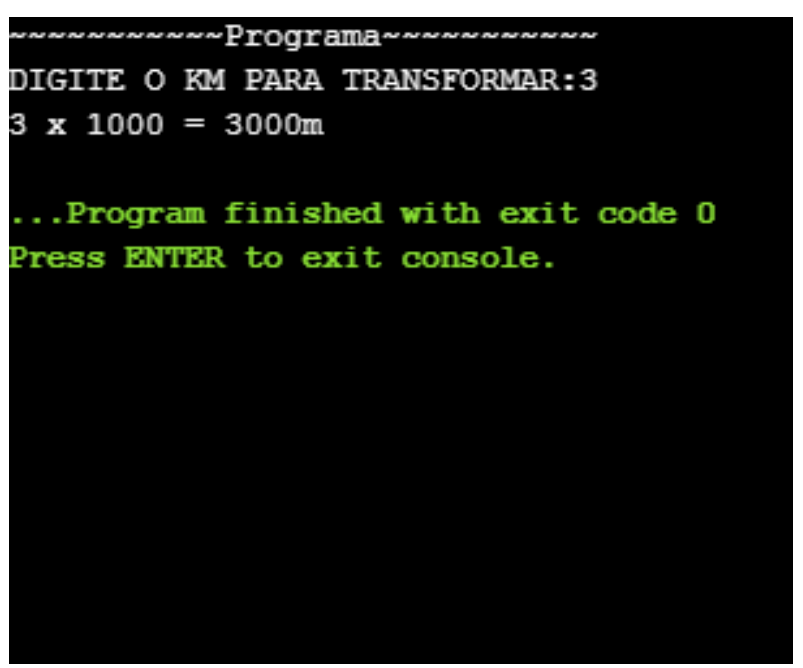

Figura 24 - Programa em C do exemplo 7 A em execução 
b) Converter $\mathrm{km} / \mathrm{h}$ para $\mathrm{m} / \mathrm{s}$

$36 \mathrm{~km} / \mathrm{h}$ pode ser escrito como $36 \frac{\mathrm{km}}{\mathrm{h}}$ vamos modificar para $\underline{\mathrm{m}}$

$36 \frac{\mathrm{km}}{\mathrm{h}} \times \frac{1000 \mathrm{~m}}{1 \mathrm{~km}} \times \frac{1 \mathrm{~h}}{3600 \mathrm{~s}}$ quando simplificamos as unidades temos:

$36 \frac{\mathbf{k m}}{\mathbf{h}} \times \frac{1000 \mathrm{~m}}{1 \mathbf{k m}} \times \frac{1 \mathbf{h}}{3600 \mathrm{~s}}=\frac{36 \times 1000 \mathrm{~m}}{3600 \mathrm{~s}} \quad \begin{gathered}\text { cortamos dois zeros para } \\ \text { simplificar }\end{gathered}$

36-x $10 \mathrm{~m}$ simplificamos o número 36 teremos $10 \underline{\mathrm{m}}$ ou geralmente $10 \mathrm{~m} / \mathrm{s}$ $36 \mathrm{~s}$

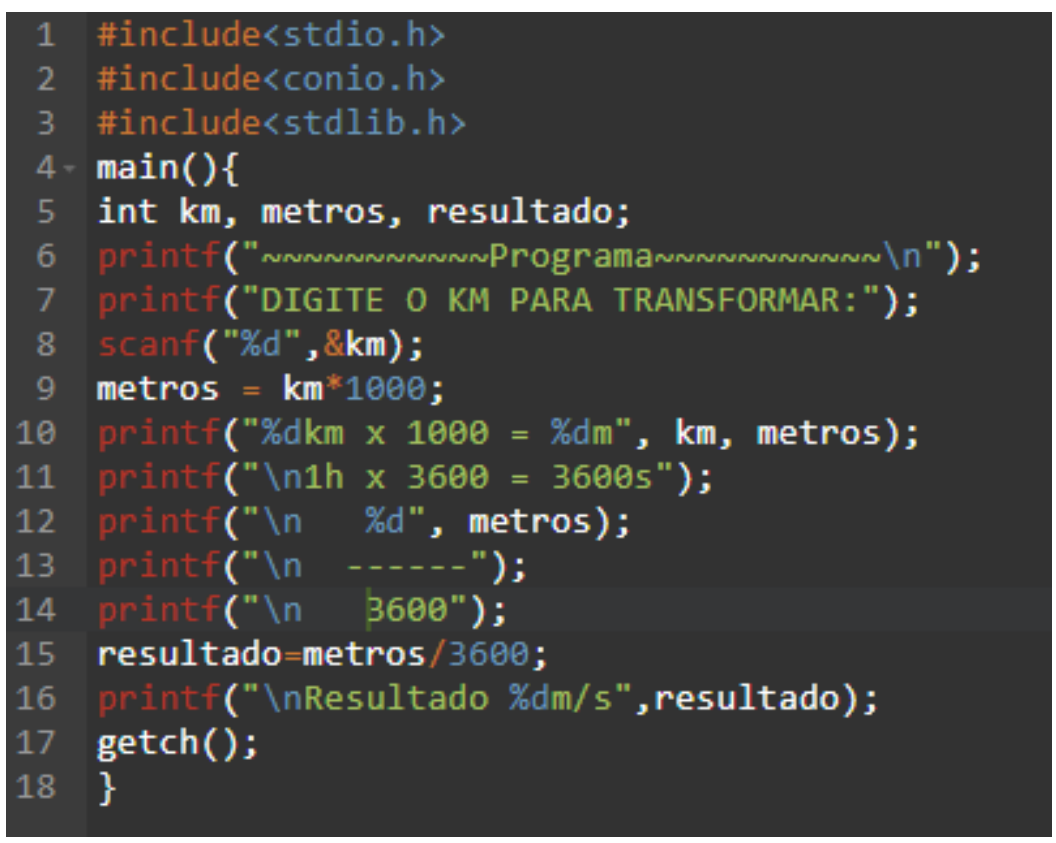

Figura 25 - Programa em C do exemplo 7 B

A execução do programa a figura 26 ilustra. 


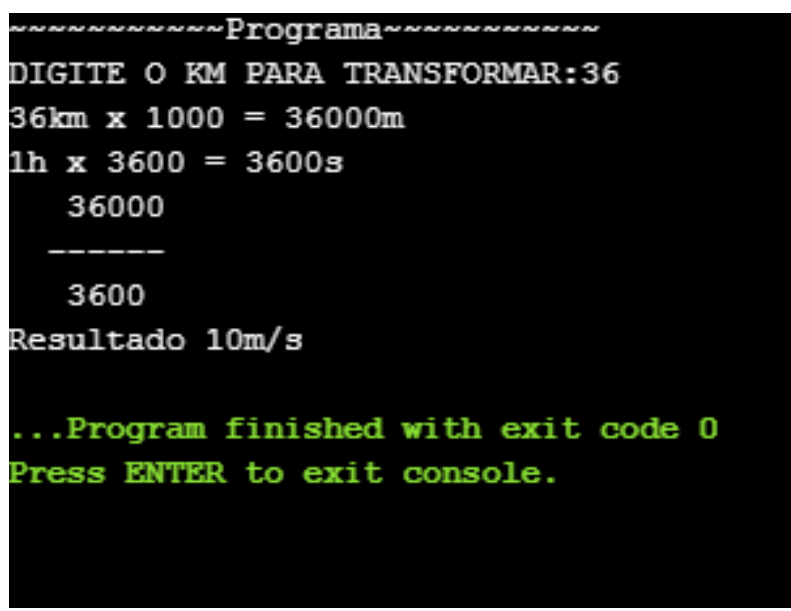

Figura 26 - Programa em C do exemplo 7 B em execução

Vamos agora pensar em um vetor que é representado por flechas (a) que podem ser decompostas no eixo da abscissa $\left(a_{x}\right)$ ou ordenada $\left(a_{y}\right)$. Resulta num triângulo retângulo que possui algumas relações, vamos utilizar apenas a mais conhecida.

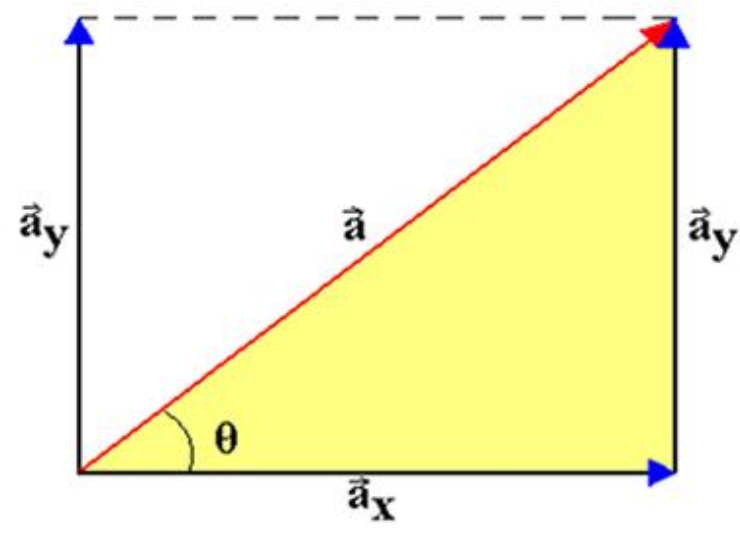

a) Teorema de Pitágoras:

Figura 27 - Pitágoras

$(a)^{2}=\left(a_{x}\right)^{2}+\left(a_{y}\right)^{2}$

\section{Exemplo 8}

Se $\mathrm{a}_{\mathrm{x}}=4$ e $\mathrm{a}_{\mathrm{y}}=3$ teremos que $(\mathrm{a})^{2}=(4)^{2}+(3)^{2}$ desenvolvendo temos

$(a)^{2}=16+9=25$ para simplificar $(a)^{2}=(5)^{2}$ colocamos os dois lados dentro da raiz quadrada para simplificar $\sqrt{a^{\mathbf{2}}}=\sqrt{5^{\mathbf{2}}}$ e $\mathbf{a}=\mathbf{5}$

Pensando de outra forma se $\mathrm{a} \times \mathrm{a}=5 \times 5$ temos $\mathbf{a}=\mathbf{5}$ 


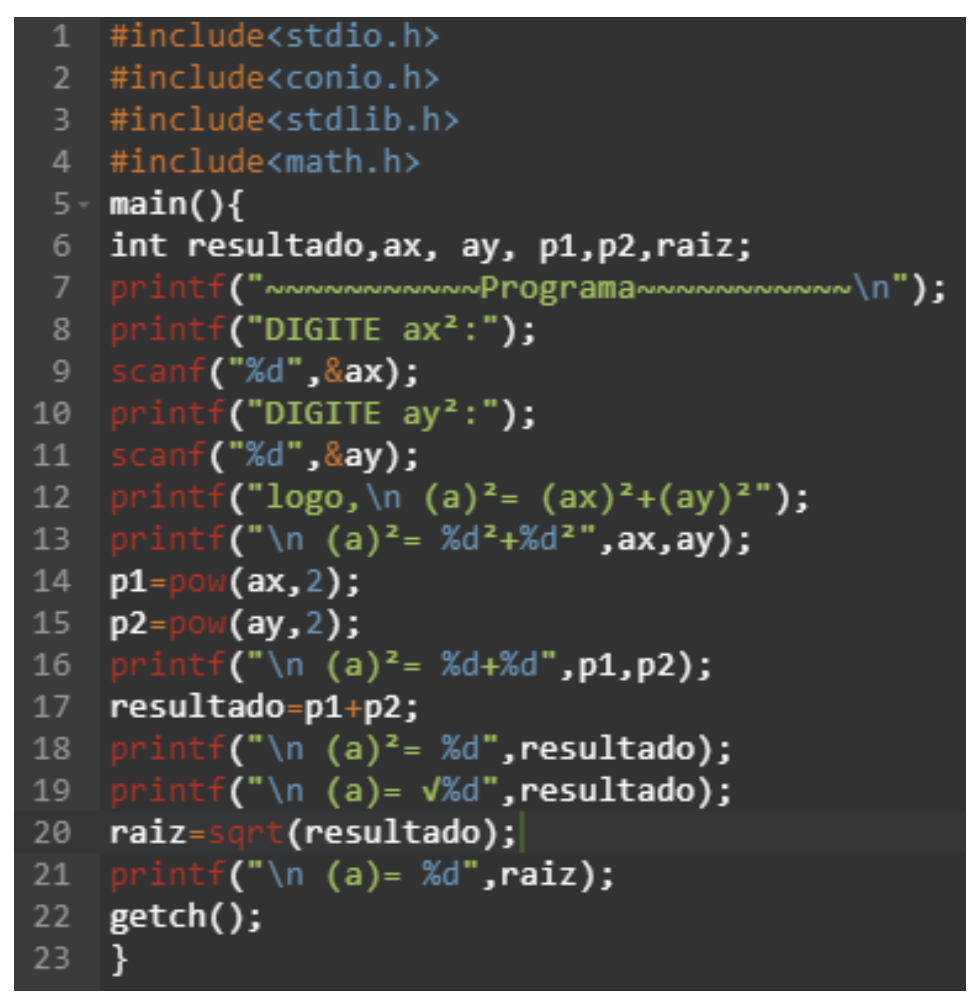

Figura 28 - Programa em C do exemplo 8

A execução do programa a figura 29 ilustra.

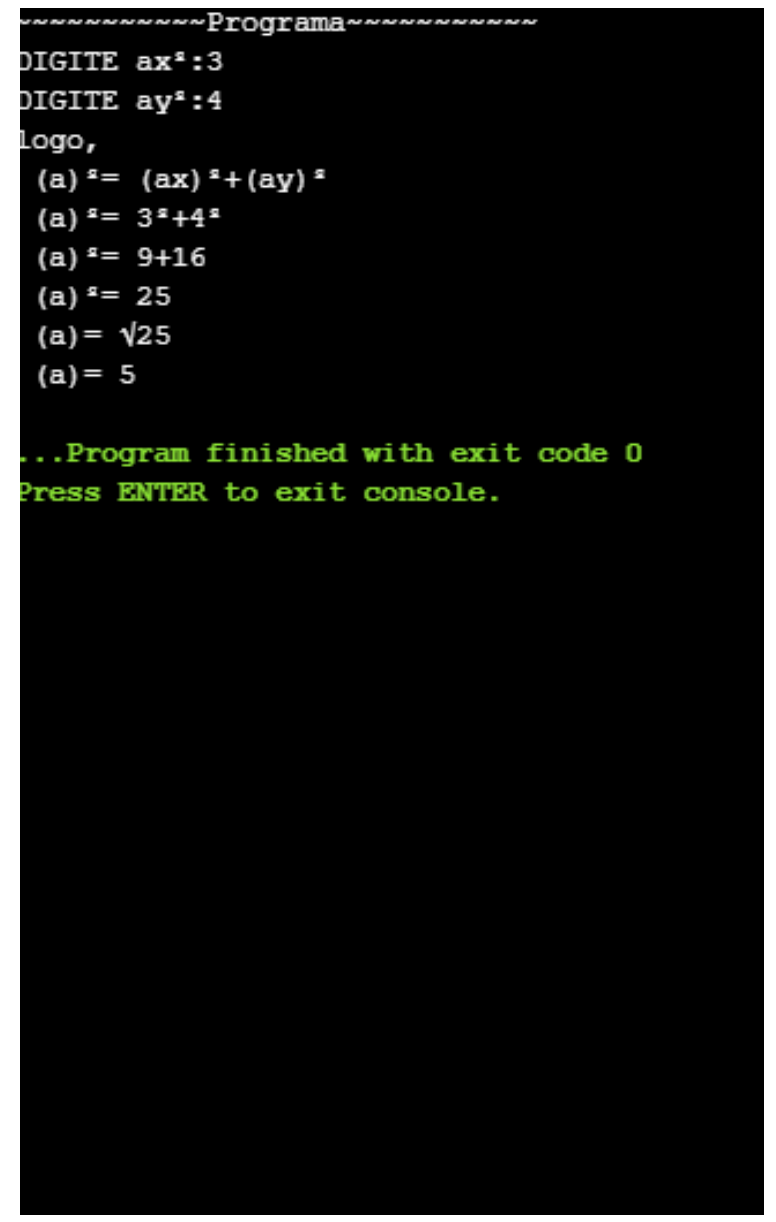

Figura 29 - Programa em C do exemplo 8 em execução 
Anotações de Física 

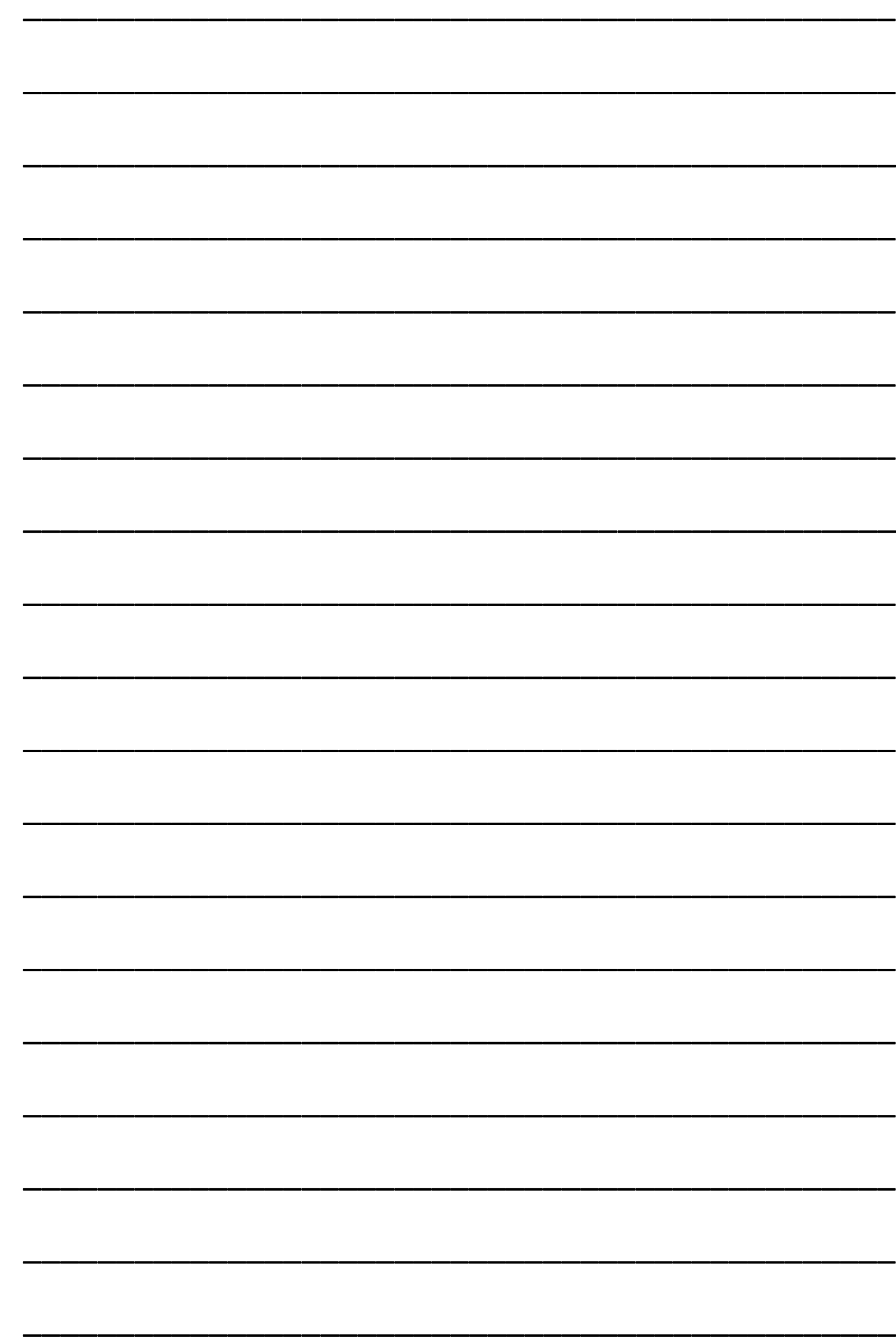
Anotações de Programação. em $C$ 

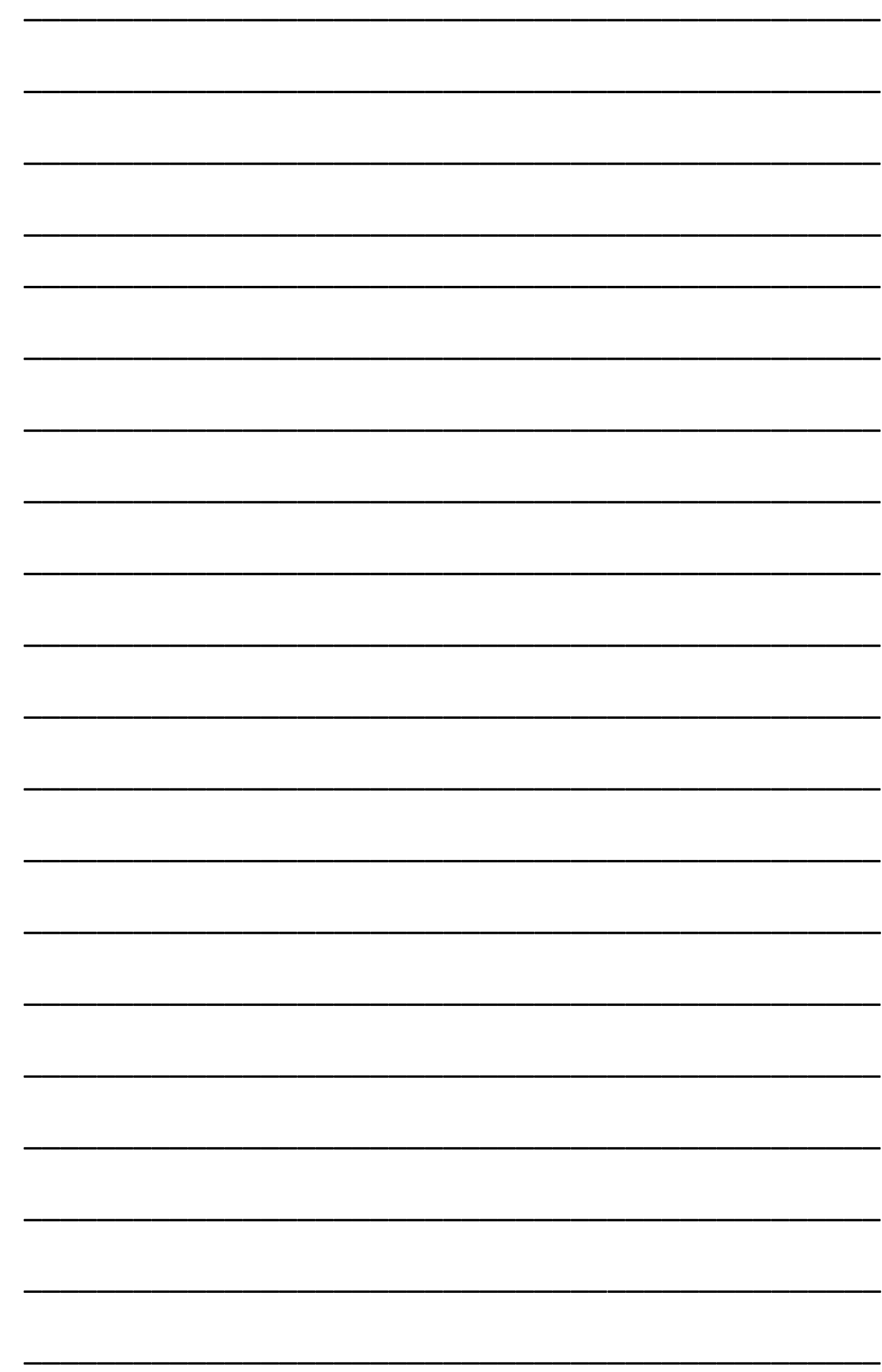


\section{SUGESTÕES!}

Para que o leitor consiga desenvolver os códigos na linguagem $\mathrm{C}$, sugerimos que acesse o sitio https://www.onlinegdb.com/online_c_compiler a fim de que possa explorar de forma online e até mesmo do seu celular observar os resultados, visto que o compilado desse site é online. A figura abaixo ilustra a interface do site.

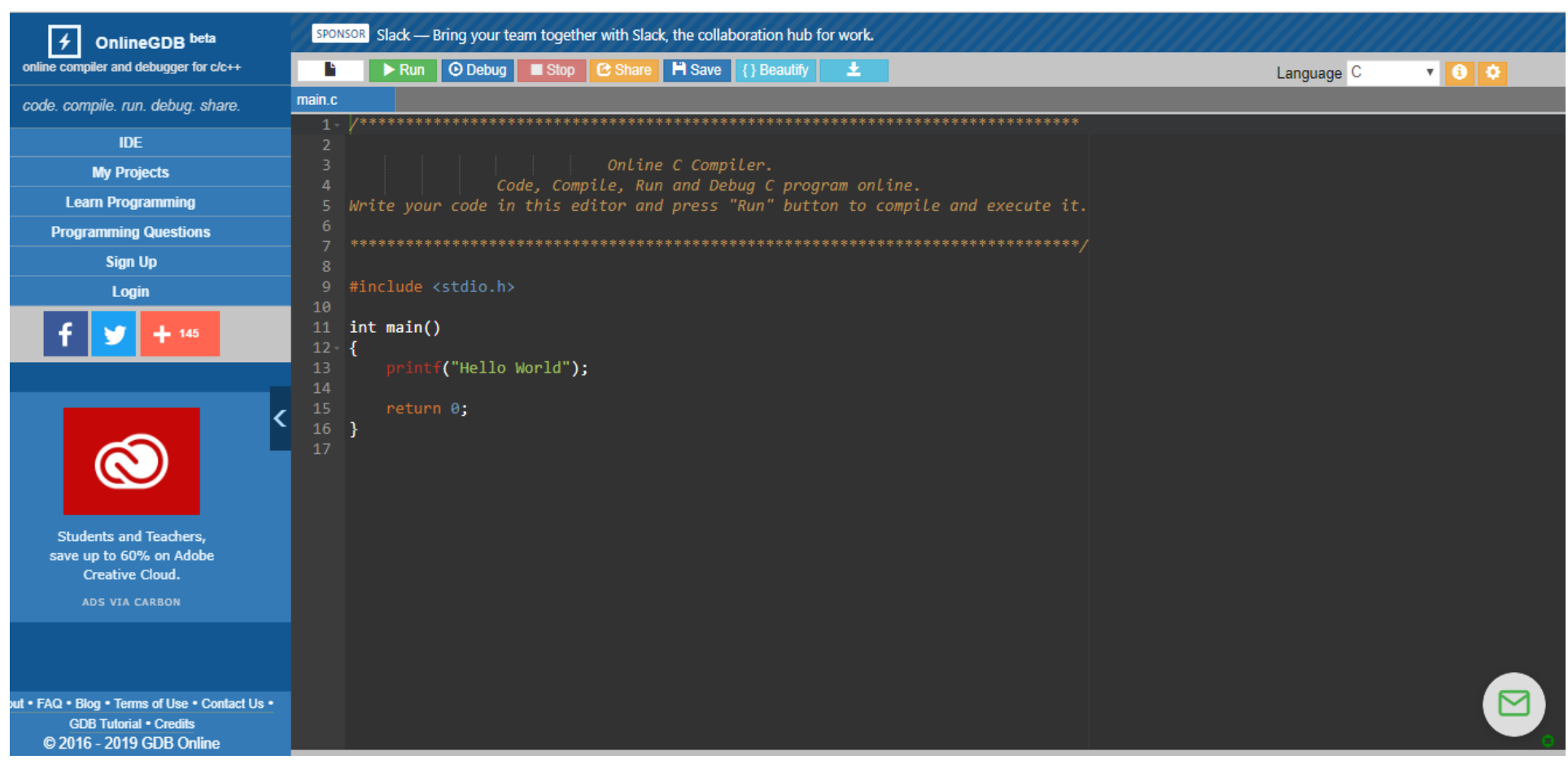

Figura 30 - Compilador C online 


\section{Conclusão}

Apresentou-se uma pequena contribuição para o público da área de exata, mas também para aqueles que são autodidatas no que diz respeito a tecnologia da informação e comunicação. Os exercícios propostos nesta obra são simples, pois visa fortalecer a base daqueles que por motivos diversos ainda sentem dificuldades para assimilação de conteúdos dessa natureza, haja vista que não são explorados apenas na disciplina de Física, mas também na matemática e até mesmo na área de programação de Jogos e sistemas digitais. Tentou-se ser o mais sucinto possível em uma linguagem de programação para que no final o aluno tem um programa onde a hora que desejar poderá fazer sua revisão com inúmeros cenários. Para o sucesso no estudo não basta apenas ouvir ou escrever o que os professores passam em sala, mas é necessária a revisão e os programas deste livro facilitará essa tarefa que não é tão trivial. Logo fechamos esta primeira etapa agora basta programar. 